\title{
Reactive oxygen species in pathogenesis of atherosclerosis
}

Nikolay V. Goncharov ${ }^{1,2}$, Pavel V. Avdonin ${ }^{3}$, Alexander D. Nadeev ${ }^{4}$, Irina L. Zharkikh ${ }^{5}$, Richard O. Jenkins ${ }^{6 *}$

${ }^{1}$ Sechenov Institute of Evolutionary Physiology and Biochemistry RAS, Saint Petersburg, Russia

${ }^{2}$ Research Institute of Hygiene, Occupational Pathology and Human Ecology, Saint Petersburg, Russia

${ }^{3}$ Koltzov Institute of Developmental Biology RAS, Moscow, Russia

${ }^{4}$ Institute of Cell Biophysics RAS, Pushchino, Russia

${ }^{5}$ Institute of General Pathology and Pathophysiology RAMS, Moscow, Russia

${ }^{6}$ School of Allied Health Sciences, De Montfort University, The Gateway, Leicester LE1 9BH, UK

* The author for correspondence; roj@dmu.ac.uk

Full citation:

GONCHAROV NV, AVDONIN PV, NADEEV AD, ZHARKIKH IL and JENKINS RO. Reactive oxygen species in pathogenesis of atherosclerosis. Current Pharmaceutical Design. 2015: 21 (9), 1134-1146. DOI: $10.2174 / 1381612820666141014142557$ 


\begin{abstract}
The volume of publications on the role of reactive oxygen species (ROS) in biological processes has been increasing exponentially over the last decades. ROS in large amounts clearly have detrimental effects on cell physiology, whereas low concentrations of ROS are permanently produced in cells and play a role as signaling molecules. An imbalance in ROS production and defense mechanisms can lead to pathological vascular remodeling, atherosclerosis being among them. The aim of this review is to examine different sources of ROS from the point of view of their participation in pathogenesis of atherosclerosis and related cardiovascular risk. Among the possible sources of ROS discussed here are mitochondria, NADPH-oxidases, xanthine oxidase, peroxidases, NO-synthases, cytochrome P450, cyclooxygenases, lipoxygenases, and hemoglobin of red blood cells. A great challenge for future research is to establish interrelations, feedback and feed-forward regulation mechanisms of various sources of ROS in development of atherosclerosis and other vascular pathologies.
\end{abstract}

Keywords: NADPH-oxidase; xanthine oxidase; peroxidase; NO-synthase; cytochrome P450; cyclooxygenase; hemoglobin.

\title{
Short 'running title': ROS \& atherosclerosis
}

Abbreviations: AII - angiotensin II, ABCA1 - ATP-binding cassette transporter A1, $\mathrm{BH}_{4}$ - tetrahydrobiopterin, COX - cyclooxygenase, CREB - cyclic adenosine monophosphate response element-binding protein, CYP cytochrome P450, EC - epicatechins, EDHF - endothelial-derived hyperpolarizing factor, EPO - eosinophil peroxidase, GPx - glutathione peroxidase, GSH - glutathione, Hb - hemoglobin, HDL - high-density lipoprotein, HETE - hydroxyeicosatetraenoic acid, IL - interleukin, LDL - low density lipoproteins, LO - lipoxygenase, LOX-1 lectin-like oxidized low-density lipoprotein, LPO - lactoperoxidase, LTs - leukotrienes, MAPK - mitogen-activated protein kinases, MIF - migration inhibitory factor, MPO - myeloperoxidase, NOS - NO-synthase, NOX - NADPHoxidase, NSAIDs - nonsteroidal anti-inflammatory drugs, PGG2 - prostaglandin G2, PGH2 - prostaglandin H2, PMA - phorbol myristate acetate, PMNs - polymorphonuclear cells, PON1 - paraoxonase 1, PS - phosphatidylserine, RBC - red blood cells, ROS - reactive oxygen species, SMC - smooth muscle cells, SOD - superoxide dismutases, TAS - total antioxidant status, TCA - tricarboxylic acid, TLR4 - toll-like receptors 4, TPO - thyroid peroxidase, XDH - xanthine dehydrogenase, XO - xanthine oxidase, XOR - xanthine oxidoreductase. 


\section{Introduction}

In the 1930th the phenomenon of oxidative (respiratory) stress in phagocytosis was described [1]. This publication gave rise to many studies on reactive oxygen species (ROS) in biological processes and systems. The ROS term refers to superoxide anion $\left(\mathrm{O}_{2}^{-}\right)$, hydrogen peroxide $\left(\mathrm{H}_{2} \mathrm{O}_{2}\right)$, hydroxyl radical $(\cdot \mathrm{OH})$, peroxyl radical (ROO•), alcoxy radical $(\mathrm{RO} \bullet)$, ozone $\left(\mathrm{O}_{3}\right)$, and singlet oxygen $\left({ }^{1} \mathrm{O}_{2}\right)$. Sometimes, reactive nitrogen species (RNS: nitric oxide or NO, hypochlorous acid, peroxinitrite) are also included [2]. The superoxide anion is a precursor for most ROS in cells, which dismutates to $\mathrm{H}_{2} \mathrm{O}_{2}$ either spontaneously or by superoxide dismutases (SOD). ROS participate in many intra- and intercellullar processes. High levels of ROS in the normal state is a characteristic function of the so called professional phagocytes - the cells of innate immunity; in the other cells, high concentrations of ROS are a sign of oxidative stress and a prerequisite of cell death. According to several studies, concentration of both endogenous (intracellular) and exogenous (extracellular) ROS can amount to as much as 500 $\mu \mathrm{M}[3,4]$. The consequences of oxidative stress caused by ROS include lipid peroxidation, break of DNA threads, and oxidation of proteins [5, 6], although these are not the only effects of ROS. For example, $\mathrm{H}_{2} \mathrm{O}_{2}$ can readily inhibit mitochondrial aconitase of the tricarboxylic acid (TCA) cycle, at concentrations not high enough to initiate lipid peroxidation [7]. Although ROS in large amounts clearly have detrimental effects on cell physiology, small amounts of ROS could have a beneficial effect, suggesting its therapeutic potential for reducing ischemic tissue [8]. Low concentrations of ROS are permanently produced in virtually every cell and tissue and play a role as the secondary messengers in redox-sensitive signaling pathways [9, 10]. $\mathrm{H}_{2} \mathrm{O}_{2}$ is the most stable and interesting molecule, from the point of view of signal transduction. The signaling effects of $\mathrm{H}_{2} \mathrm{O}_{2}$ are mainly directed towards post-translational modification of proteins due to oxidation of the thiol groups of cysteine. Extracellular $\mathrm{H}_{2} \mathrm{O}_{2}$ can enter the cells through diffusion, though entry is mainly via aquaporin channels which determine the localisation and specificity of $\mathrm{H}_{2} \mathrm{O}_{2}$ effects [11]. Signaling effects of ROS are a long-known phenomenon, and Peter Proctor in 1972 was the first to suggest their special functions [12]. During the past 40 years a plethora of papers and comprehensive reviews have been published, with a review by Proctor among the first [13, 14, 15].

Oxidative stress is involved in various pathological vascular remodeling. These injuries can be minimized by other cells, reducing molecules and anti-oxidative enzymes, both intra- and extracellular: cystein (Cys), glutathione (GSH), glutathione peroxidases (GPx), thioredoxins, peroxiredoxins, SOD, catalaze, serum paraoxonase 1 and even albumin $[6,16,17,18]$. It is clear that imbalance between ROS generation and neutralization is the principal cause of vascular and other pathologies. The aim of this review is to examine different sources of ROS from the point of view of their participation in pathogenesis of atherosclerosis and related cardiovascular risk. Among the sources of ROS are intracellular organelles (e.g. mitochondria), and enzymes such as xanthine oxidase, 
myeloperoxidase (MPO), lactoperoxidase (LPO), uncoupled NO-synthase (NOS), cyclooxygenase (COX), lipoxygenase (LO), hemoglobin (Hb), cytochrome P450 (CYP) and NADPH-oxidases (the number of which is now reported to be seven; NOX1-5 and DUOX1/2) [14, 15, 19, 20 , 21].

\section{NADPH-oxidases}

While there are many possible sources of ROS, nicotinamide adenine dinucleotide phosphate (NADPH) oxidases (NOX) play a central role. They are a source of "kindling radicals," which affect other enzymes, such as nitric oxide synthases, xanthine oxidase, etc. This is important as risk factors for atherosclerosis (hypertension, diabetes, hypercholesterolemia, and smoking) regulate the expression and activity of NOX in the vessel wall [15]. NOX are the main sources of the superoxide anion in various pathological states of the cardiovascular system. The principal difference between NOX and other sources of ROS is that for the former the generation of ROS is their major function [22]. NOX are present in neutrophils where they mostly determine the non-specific immune response [23]. In the ischemic-reperfusion condition, NOXs substantially determine tissue injury through generating ROS in endothelial and smooth muscle cells (SMC) of blood vessels.

NOX1 has been found in the plasma membrane of endothelial and SMC, located mainly in caveolae membranes next to caveolin [24]. NOX1 regulates proliferation and motility of SMC and takes part in blood pressure regulation [25]. The enzyme is involved in progression of hypertension initiated by angiotensin II [26, 27]. Elevated activity of NOX1 in SMC results not only in elevated level of superoxide anion but also to uncoupling of endothelial NOS (eNOS) as a result of oxidation of tetrahydrobiopterin $\left(\mathrm{BH}_{4}\right)$, thus making eNOS an additional source of superoxide [28]. Moreover, superoxide generated by NOX1 (and probably by other NOXs) converts xanthine oxidoreductase to xanthine oxidase [29].

NOX2 is the most studied isoform of NOX, which generates superoxide anions in professional phagocytes and many other cells. In phagosomes, superoxide interacts with chloride ions under catalytic control of myeloperoxidase, with production of hypochlorite [30]. Activation of the lipoxygenase signaling pathway is also coupled with activation of NOX2, when ligands CD154 or CD40L interact with CD40 of B lymphocytes [31, 32]. Associated factors of TNF-receptor (TRAF) -PI3 kinase and small G-protein Rac1 - are involved in this signaling pathway. Synergism in effects of ligands of CD40 and oxidative stress developed after activation of NOX in ischemic-reperfusion conditions lead to death of hepatocytes and probably endothelial cells, which also express CD40 in stress conditions [33, 34].

NOX1/2 promote the development of endothelial dysfunction, hypertension, and inflammation [15]. For activation of NOX1/2 an interaction of several regulatory subunits is necessary: Ncf1/p47phox (NOX1 and NOX2); 
Cyba/p22 $2^{\text {phox }}$; Noxa1, Noxo1 (a homolog of p47 phox , NOX1); small G-protein Rac (NOX1 and NOX2) [23, 35]. As distinct from NOX1 and NOX2, functionally active NOX4 consists of only two proteins, Nox4 and p22 $2^{\text {phox }}$ [36]. NOX4 is located in the endoplasmic reticulum and nucleus [24, 37]. NOX4 has been found in endothelial cells, where it is the principal source of ROS, and also in many other cells: fetal liver, SMC, osteoclasts, hemopoietic stem cells, adipocytes and cardiomyocytes [38, 39]. It is supposed that NOX4 is part of the oxygen sensor system in proximal tubules of kidneys, carotid body type I cells, SMC of lung artery, neuroepithelial bodies of pulmonary airways, heart fibroblasts, and probably in other cells [24, 40, 41]. It was first suggested that NOX4 generates superoxide, which can neutralize NO produced in the same cells [37], but later it was established that NOX4 generates $\mathrm{H}_{2} \mathrm{O}_{2}[42,43]$. Activators of other NOX isoforms do not affect activity of NOX4, and generation of $\mathrm{H}_{2} \mathrm{O}_{2}$ in the cells depends upon expression of NOX4; activity of the enzyme is therefore constitutive and there is no need for regulatory subunits to be activated [42].

Nonetheless, regulation of NOX4 does exist and studies of the regulatory mechanisms could improve understanding of the pathogenesis of many diseases, including atherosclerosis. For example, insulin activates NOX4 in 3T3-L1 fibroblasts and the $\mathrm{H}_{2} \mathrm{O}_{2}$ produced inhibits tyrosine phosphatases enhancing tyrosine phosphorylation [44]. Toll-like receptors 4 (TLR4) also activate NOX4 under ischemia/reperfusion; this activation plays a key role in development of inflammation and is an important prerequisite of kidney and brain injuries [45, 46]. TGF-beta induces transformation and proliferation of SMC and endothelial cells by ROS generated via NOX4 [47, 48]. 7Ketocholesterol, which is the principal component of low density lipoproteins (LDL), stimulates expression of NOX4 and apoptosis in SMC of blood vessels [49]. Plaque instability associated with acute coronary syndromes results in part from apoptosis and senescence of cells within the atherosclerotic lesion. An age-dependent increase in ROS in aorta from atherosclerotic mice has been observed, with evidence for elevated ROS prior to lesion development [50]. Whereas macrophage infiltration was restricted to the lesion, oxidized lipids extended beyond the plaque and into the vessel wall. Consistent with these findings, dynamic changes in the expression of NADPH oxidases in atherosclerotic vessels were observed. Specifically, Nox1 protein expression was increased early and decreased with lesion progression, while induction of Nox4 was a late event. Nox2 and p22 $2^{\text {phox }}$ proteins were elevated throughout lesion development. Atherosclerotic SMC demonstrated increased generation of ROS, cell cycle arrest, evidence of senescence, and increased susceptibility to apoptosis [50]. Interestingly, NOX4 may have a role in protecting the vasculature during stress; however, when its activity is increased, it may be detrimental. Also, calcium-dependent NOX5 has been implicated in oxidative damage in human atherosclerosis [15]. It is noteworthy here that NOX5 is expressed in primates but does not occur naturally in rodents. 
NADPH oxidases of the DUOX group (DUOX1 and DUOX2) also generate $\mathrm{H}_{2} \mathrm{O}_{2}$ [51, 52]. DUOX1/2 are sources of $\mathrm{H}_{2} \mathrm{O}_{2}$ for LPO, playing an important role in antibacterial activity of saliva, milk, lacrimal fluid and secretion of air-conducting pathways [51]. DUOX2 (and probably DUOX1) are functionally bound with thioperoxidase (TPO) and participate in biosynthesis of thyroid hormones generating $\mathrm{H}_{2} \mathrm{O}_{2}$ through intramolecular dismutation of superoxide [53]. TPO utilize iodide ions and $\mathrm{H}_{2} \mathrm{O}_{2}$ for generation of molecular iodine, which is necessary for biosynthesis of thyroid hormones $\mathrm{T}_{3}$ and $\mathrm{T}_{4}$. NOX4, together with DUOX2, is a source of $\mathrm{H}_{2} \mathrm{O}_{2}$ in the thyroid gland. Insufficient quantity of $\mathrm{H}_{2} \mathrm{O}_{2}$ is a cause of hypothyroidism, whereas elevated synthesis of $\mathrm{H}_{2} \mathrm{O}_{2}$ is observed in papillary thyroid carcinoma [54]. As for blood vessel pathologies, low normal thyroid function may adversely affect lipoprotein metabolism and atherosclerosis development. Subclinical hypothyroidism is associated with endothelial dysfunction [55]. Vascular SMC apoptosis is an early trigger of hypothyroidism-associated atherosclerosis, and activation of thyroid hormone receptors TR $\alpha 1$ to prevent vascular SMC apoptosis could be a therapeutic strategy in this disease [56].

\section{Mitochondria}

In mitochondria, oxygen can be reduced with one or two electrons to produce superoxide and $\mathrm{H}_{2} \mathrm{O}_{2}$, respectively [57]. The respiratory chain is the main source of superoxide in one-electron mitochondrial reduction of oxygen. Complex I supplies electrons for matrix oxygen, though complex III - for matrix and intermembrane space

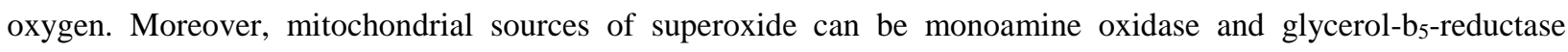
(located on outer mitochondrial membrane), glycerol-3-phosphate dehydrogenase and cytochrome P450 (located on inner mitochondrial membrane), aconitase, pyruvate dehydrogenase, and $\alpha$-ketoglutarate dehydrogenase (matrix enzymes). Two-electron mitochondrial reduction of oxygen in mitochondria takes place due to interaction of cytochrome C (cytC) and the p66shc adaptor protein. Superoxide of mitochondrial matrix dismutates to produce $\mathrm{H}_{2} \mathrm{O}_{2}$ due to Mn-SOD (SOD2), whereas superoxide of the intermembrane space - due to cytosolic Cu,Zn-SOD (SOD1) [58]. Mitochondrial-derived reactive oxygen species (mtROS) is one of the major sources of cellular ROS, and excessive mtROS is associated with atherosclerosis progression in both human and mouse models. Despite numerous association and causation studies demonstrating the importance of mtROS in atherosclerosis progression, the failure of antioxidant therapy in human randomized clinical trials demands more definitive, cell-type specific investigations [59]. For example, it was demonstrated that mitochondrial ROS of endothelial cells contribute to initiation of inflammatory reactions via NFkB to recruit leukocytes into the intima [60]. The successive oxidative burst in activated neutrophils can greatly exceed the initial generation of ROS by endothelium, bringing forth irreversible injuries to the cells [61]. In addition, mitochondrial oxidative stress in lesional macrophages amplifies 
atherosclerotic lesion development by promoting NF-кB-mediated entry of monocytes and other inflammatory processes [62]. ROS interacts with ionic channels, cytoskeletal and adhesive proteins, enhancing endothelial permeability due to activation of contractile proteins and degradation of occludin, the principal tight junction protein $[63,64]$. It also should be noted that mitochondrial DNA (mtDNA) defects promote atherosclerosis and plaque vulnerability independently of ROS, through effects on vascular SMC and monocytes. MtDNA damage is therefore not only causative, but also indicates higher risk for atherosclerosis [65].

\section{Xanthine oxidoreductase}

The enzyme xanthine oxidoreductase (XOR) catalizes the two last stages of degradation of purines (hypoxanthine $\rightarrow$ xanthine $\rightarrow$ uric acid). The initial transcription product of a single gene is NAD-dependent xanthine dehydrogenase (XDH, EC 1.17.1.4). Molybdenum-containing cofactor of XDH transfers electrons from substrate through Fe/S centres to FAD-containing cofactor followed by reduction of NAD: $x a n t h i n e+\mathrm{NAD}^{+}+\mathrm{H}_{2} \mathrm{O}$ $\rightleftharpoons$ uric acid $+\mathrm{NADH}+\mathrm{H}^{+}$. However, a post-translational oxidative modification of cysteine residue or irreversible proteolytic modification transforms XDH to oxygen-dependent xanthine oxidase (XO, EC 1.17.3.2) [66, 67]. As a result, the affinity decreases for NAD and increases for oxygen, and electrons proceed from the substrate via $\mathrm{Mo}^{2+}$ cofactor to FAD cofactor, with production of $\mathrm{H}_{2} \mathrm{O}_{2}$ : hypoxanthine $+\mathrm{H}_{2} \mathrm{O}+\mathrm{O}_{2} \rightleftharpoons$ xanthine $+\mathrm{H}_{2} \mathrm{O}_{2}$; xanthine + $\mathrm{H}_{2} \mathrm{O}+\mathrm{O}_{2} \rightleftharpoons$ uric acid $+\mathrm{H}_{2} \mathrm{O}_{2}$. Also, in some conditions one-electron reduction of oxygen occurs and the superoxide-anion is produced: $\mathrm{RH}+\mathrm{H}_{2} \mathrm{O}+2 \mathrm{O}_{2} \rightleftharpoons \mathrm{ROH}+2 \mathrm{O}_{2}^{-}+2 \mathrm{H}^{+}$. Moreover, XDH can also generate superoxide when $\mathrm{NAD}^{+}$is in deficit (for example, during inflammation and concomitant hypoxic microenvironment of the enzyme, though before XDH transforms to XO) $[68,69]$. According to recent data, $\mathrm{XO}$ is a major contributor to oxidative stress [70]. In the atherosclerotic plaque, XO-mediated ROS formation is pro-inflammatory and XOinhibition by febuxostat is a potential therapy for atherosclerosis [71]. However, allopurinol or siRNA against XO does not exhibit a protective effect against cell death suggesting that XO-generated $\mathrm{H}_{2} \mathrm{O}_{2}$, and perhaps $\mathrm{H}_{2} \mathrm{O}_{2}$ in general, is a consequence but not a mediator of cell death [70].

There is another possible reason for low efficiency of allopurinol. It was shown earlier that during diverse pathologic processes, XO released into plasma from tissues can circulate to remote sites and bind to target tissues low in or devoid of XO activity. Cell-bound XO may then be concentrated several thousand-fold at the cell surface or interstitial matrix, where its oxidant products could more readily react with cellular target molecules and disrupt vascular functional and barrier properties [72]. High concentrations of XO associate with endothelial cell glycosaminoglycans resulting in significant resistance to inhibition by traditional pyrazolopyrimidine-based 
inhibitors such as allopurinol [73]. A new nonpurine XO-specific inhibitor - febuxostat - was shown to have superior potency for inhibition of endothelium-associated $\mathrm{XO}$, as compared with allopurinol, and could be an efficient potential therapy for atherosclerosis [71].

\section{Cytochromes P450}

Cytochromes P450 (CYP) is a big group (superfamily) of heme-containing enzymes, which for a long time were considered to be flavin-containing monooxygenases of endoplasmic reticulum exclusively in liver, the function of which is oxygen- and NADPH-dependent oxidation and/or reduction of cholesterol, vitamins, steroids, and many other compounds. It was later revealed, however, that some enzymes of this superfamily are expressed in many tissues beyond liver, including the cells of cardiovascular system [74]. The CYP enzymes metabolizing arachidonic acid (families CYP2 and CYP4A) participate in vascular tone regulation, generating vasoactive derivatives of fatty acids and ROS. Thus, 20-HETE is produced in vascular SMC due to CYP4A activity, and CYP2C8/9 of endothelial cells produce epoxyeicosatrienoic acids responsible for NO- and $\mathrm{PGI}_{2}$-independent endothelial-dependent relaxation of blood vessels caused by a hyperpolarizing factor $[74,75]$. Like other CYP enzymes, CYP2C is inhibited by NO and therefore work in environments with minimal NO concentration. It has been found that CYP enzymes of blood vessels can generate superoxide anion, $\mathrm{H}_{2} \mathrm{O}_{2}$ and hydroxyl radical; this takes place during the NADPH-dependent transfer of electrons, which were intended for reduction of heme iron in oxygen generation [74]. In endothelial cells, CYP2C participates in generation of endothelial-derived hyperpolarizing factor (EDHF) and at the same time is a source of ROS [76]. CYP2C can produce both EDHF (vasodilator) and ROS (vasoconstrictors in case of inactivation of $\mathrm{NO}$ and vasodilator in case of generation of $\mathrm{H}_{2} \mathrm{O}_{2}$ ), therefore modulation of CYP2C activity is not always predictable, especially taking into account activity of other sources of ROS. For example, superoxide anion produced by CYP2C impairs the NO-dependent vascular relaxation and enhances activity of redox-sensitive nuclear factor NFkB and expression of VCAM-1 [76]. Inhibition of CYP2C9 by sulfaphenozole normalise endotheliumdependent NO-mediated dilation in patients with coronary artery disease [77]. A trigger role of CYP-generated ROS in pro-inflammatory effects of TNF-a has been demonstrated, which elevated expression of addressin genes (MAdCAM-1) and some other adhesion molecules of high endothelial venule; inhibitors of CYP (ketoconazole and others) blocked the effects of TNF-a [78]. In addition, expression by endothelial cells of E-selectin (CD62), ICAM-1 (CD54), VCAM-1 (CD106) depend upon ROS produced by NOX, mitochondria, XO and eNOS [78, 79, 80]. Conversely, expression and activity of endothelial CYP is stimulated by circular stretch of blood vessels, hormones, and inhibitors of HMG-CoA reductase [75, 81]; all of these induce elevation of both ROS and EDHF. 
Expression of CYP increases during hypertension and hypercholesterolemia. It is worth noting that oxidized LDL (oxLDL) decreases the level of expression of CYP2 in endothelium due to $\mathrm{H}_{2} \mathrm{O}_{2}$ produced by NOX-4, and decreases expression of transcriptional regulator NF-1 by interacting with the promotor region of CYP [82]. Because of the injuring effects of oxLDL upon blood vessels, a blockade of lectin-like receptors for oxLDL (LOX1) could be an efficient therapeutic means, which would regenerate activity of CYP.

\section{NO-synthases}

NO-synthases are homodimeric oxidoreductases which provide electron transfer from the C-terminal reductase to the N-terminal oxidase domain. Cofactors FAD and FMN are connected with the reductase domain to provide electron transfer from $\mathrm{NADPH}$. Heme prosthetic group, $\mathrm{BH}_{4}$, oxygen and L-arginine are bound to the oxidase domain; also, there is a site for binding calmodulin. The structure of the reductase domain is similar to that of CYP-enzymes, so in the case of "uncoupling” of the NOS superoxide anion would be a product of reaction instead of $\mathrm{NO}[83,84] . \mathrm{BH}_{4}$ provides the coupling of two processes, reduction of molecular oxygen and oxidation of arginine; moreover, $\mathrm{BH}_{4}$ stabilizes the dimeric structure of NOS [85]. ROS oxidize $\mathrm{TH}_{4}$ to produce dihydrobiopterin, which competes with $\mathrm{TH}_{4}$ for binding with NOS and promotes uncoupling and further generation of ROS. The principal factor of uncoupling is a ratio of $\mathrm{BH}_{4}$ to total biopterin: at concentration of the latter above $1.5 \mu \mathrm{M}$ the uncoupled eNOS can simultaneously produce $\mathrm{NO}$ and $\mathrm{O}_{2}^{-}$, they react to generate peroxinitrite, which is another uncoupler of NOS [85].

It has recently been reported that oxLDL binding to lectin-like oxidized low-density lipoprotein (LOX-1) determined a significant increase in the generation of ROS, suggesting the involvement of signaling pathways such as mitogen-activated protein kinases (MAPK) [86]. LOX-1 has been identified in endothelial cells as the main receptor of oxLDL. LOX-1 is upregulated in the presence of pathological conditions including atherosclerosis, hypertension and diabetes, because it acts as a mediator of "endothelial dysfunction". It promotes the generation of $\mathrm{O}_{2}^{-}$, the inhibition of NO production and the increase of endothelial adhesiveness to monocytes. Also, oxLDL inhibits macrophage migration and traps foam cells, possibly through oxLDL induced iNOS expression. Therefore, reduction of peroxynitrite and possibly lipid hydroperoxide levels in plaques represents a valuable therapeutic approach to reverse migratory arrest of macrophage-derived foam cells and to impair plaque formation [86]. In addition, ceramide may be an important target for preventing and treating vascular dysfunction associated with atherosclerosis, since it has been shown that ceramide has an integral role in the transition of NO synthesis to mitochondrial-derived $\mathrm{H}_{2} \mathrm{O}_{2}$, which regulates flow-induced dilation in microvessels [87]. 


\section{Peroxidases}

Peroxidases (EC 1.11.1.x) are widely distributed in the animal and plant kingdoms, they catalize reactions of one- and two electron oxidation of various substrates according to the general scheme: ROOR' + electron donor $\left(2 \mathrm{e}^{-}\right)+2 \mathrm{H}^{+} \rightarrow \mathrm{ROH}+\mathrm{R}^{\prime} \mathrm{OH}$. Recently phylogenetic relations were established for the major lines of evolution of the heme-containing animal peroxidases: myeloperoxidase (MPO), eosinophil peroxidase (EPO), lactoperoxidase (LPO) and thyroid peroxidase (TPO) [88]. On the basis of their prevalence and two types of enzyme activity intrinsic to these proteins, a new superfamily of peroxidases/cyclooxygenases were classified and divided into seven subfamilies, the first of which includes heme peroxidases of the vertebrata. Enzymes of this subfamily are constituents of inner immunity (MPO, EPO, LPO), and also participate in biosynthesis of hormones (TPO, see above). Peroxidases consists of one (monomeric EPO and LPO) or two (homodimeric MPO and TPO) glycosylated alpha-helical (predominantly) domains with one autocatalytically modified heme in each domain [89].

MPO is a component mainly of the azurophilic granules of neutrophils. The product of activity of this enzyme is hypochlorous acid $\mathrm{HOCl}$, which is generated in phagosomes from $\mathrm{H}_{2} \mathrm{O}_{2}$ and $\mathrm{Cl}^{-}$during the respiratory burst of neutrophils [30]. Moreover, MPO with the help of $\mathrm{H}_{2} \mathrm{O}_{2}$ oxidizes thyrosine to thyrosine-radical, which is also cytotoxic along with hypochlorite and serves to combat against bacteria and other pathogens [90]. MPO is one of the factors promoting oxidative/halogenating modification of LDL. Both monocytes (which differentiate into macrophages) and neutrophils secrete MPO in response to the presence of damaged LDL. Binding to MPO is important for LDL to become modified and acquire proatherogenic properties. MPO binds to the LDL surfaces, and the LDL-MPO complex is uncoupled in the presence of peptide EQIQDDCTGDED that corresponds to a fragment of apoB-100. The EQIQDDCTGDED peptide, ceruloplasmin, and $\mathrm{SCN}^{-}$can play the role of anti-atherogenic factors reducing the deleterious effect of catalytically active MPO on LDL and accumulation of cholesterol in macrophages [91]. Serum MPO levels and paraoxonase 1 (PON1) activities were significantly associated with the prevalence of coronary lesions. PON1 has antioxidant properties for high-density lipoprotein (HDL). A high MPO/PON1 ratio, when cut-off values were set at 1.59, was independently correlated with restenosis and de novo lesions. HDL isolated from patients with low serum MPO/PON1 ratio inhibited VCAM-1 expression, which may participate in monocyte recruitment to atherosclerotic sites, significantly greater than that with high MPO/PON1 ratio. The cholesterol efflux capacity of apoB-depleted serum from patients with high MPO/PON1 ratio was significantly lower than that with low MPO/PON1 ratio [92]. As for the mechanism, MPO may contribute to the generation of dysfunctional HDL with impaired ATP-binding cassette transporter A1 (ABCA1) efflux capacity in humans with atherosclerosis. Subjects with coronary artery disease and acute coronary syndrome had higher levels of chlorinated 
Tyr192 and oxidized Met148 compared with control subjects. In contrast, plasma levels of MPO did not differ between the groups. HDL from the subjects with coronary artery disease and acute coronary syndrome was less able to accept cholesterol from cells expressing ABCA1 compared with HDL from control subjects. Levels of chlorinated tyrosine and oxidized methionine were inversely associated with ABCA1 efflux capacity and positively with atherosclerotic disease status. Quantification of chlorotyrosine and oxidized methionine in circulating HDL might be useful indicators of the risk of cardiovascular disease that are independent of HDL-cholesterol [93]. It is worth noting that epicatechins (EC) are substrates for peroxidases including the neutrophil-derived MPO. Oxidation of the catechol moiety of EC to a $o$-quinone by MPO generates potent macrophage migration inhibitory factor (MIF) inhibitors. MIF is implicated in a number of inflammatory diseases including sepsis, arthritis and colitis, and in diseases with an inflammatory component, such as atherosclerosis, diabetes and cancer. MIF has an unusual Nterminal proline with catalytic activity, and targeting of this residue by small molecule inhibitors has been shown to interfere with the biological activity of MIF. Near complete inhibition of MIF by the $\mathrm{MPO} / \mathrm{H}_{2} \mathrm{O}_{2} / \mathrm{EC}$ system was achieved at equimolar concentrations of EC and MIF even in the presence of other MPO substrates. The modification introduced by oxidized EC on MIF occurs at the N-terminal proline. MIF inhibition by oxidized EC contributes to the anti-inflammatory activity of these compounds [94].

LPO catalyzes oxidation of some substrates with $\mathrm{H}_{2} \mathrm{O}_{2}$ according to a general scheme: substrate $+\mathrm{H}_{2} \mathrm{O}_{2} \rightarrow$ oxidized substrate $+\mathrm{H}_{2} \mathrm{O}$. The most significant physiological implication has oxidation of thiocyanate (SCN $)$ and bromide $\left(\mathrm{Br}^{-}\right)$, with hypothiocyanate $\left(\mathrm{OSCN}^{-}\right)$and hypobromide $\left(\mathrm{BrO}^{-}\right)$being produced, respectively. As for the secondary or intermediate products of halide oxidation, singlet oxygen and other ROS were revealed [95, 96]. $\mathrm{H}_{2} \mathrm{O}_{2}$ is produced from glucose and oxygen via glucose oxidase (EC 1.1.3.4). Another source of $\mathrm{H}_{2} \mathrm{O}_{2}$ for $\mathrm{LPO}$ is DUOX1/2 [51]. In some conditions LPO can enhance oxidative stress and the toxic effects of $\mathrm{H}_{2} \mathrm{O}_{2}$, for example with excess thiocyanate in the reaction medium [97]. Another example is oxidation of estradiol in breast cancer [98]. In addition, LPO can enhance the carcinogenic potential of aromatic and heterocyclic amines [99]. There are scarce data on the specific role of LPO in pathogenesis of atherosclerosis. LPO, prostaglandin synthetase, prostacyclin synthetase, though mainly myeloperoxidase, can generate toxic methyl glyoxal through catalyzed peroxidation of acetoacetate, and this has been proposed to be a link between cardiovascular risk factors and the initiation of atherosclerosis [100].

EPO is a haloperoxidase utilizing bromide as a substrate, which is necessary for eosinophils to combat multicellular pathogens (e.g. nematode worms) and some bacteria (e.g. Mycobaterium tuberculosis) [101]. This is a heterodimer of 71-77 $\mathrm{kDa}$ with glycosylated (more heavy) and non-glycosylated (less heavy) subunits [102]. Excessive activity of EPO and NOX, and enhanced generation of ROS is observed in some diseases, such as asthma 
[103]. As with LPO, there is little evidence of direct cause-effect relations between EPO and atherosclerosis development. EPO may activate histamine release by basophils and mast cells. The content and release of heparin and histamine may play a role in preventing thrombus formation and in promoting lipolysis. The cytoplasmic lipid accumulation by neutrophils, basophils and mast cells may in turn contribute to the population of foam cells in these lesions [104]. Patients with allergic disorders such as allergic rhinitis or asthma have been reported to be at increased risk for atherosclerosis, and there is a relationship between peripheral eosinophil count and degree of albumin excretion rate, which is a useful marker of cardiovascular mortality as well as diabetic nephropathy in patients with type 2 diabetes [105].

\section{Cyclooxygenase and Lipoxygenases}

Cyclooxygenase (COX, prostaglandin-endoperoxide synthase, prostaglandin H2 synthase, EC 1.14.99.1) has two active centers: one of these provides the cyclooxygenase activity per se, arachidonic acid (20:4, $\omega-6)$ being the substrate that is transformed to 15-hydroperoxy-PG endoperoxide (prostaglandin G2, PGG2); the second active center contains heme which provides peroxidase activity of the enzyme transforming PGG2 to prostaglandin $\mathrm{H}_{2}$ $\left(\mathrm{PGH}_{2}\right)$. In addition, the "peroxidase center" of COX generates a tyrosyl radical in Tyr385, which makes possible the initiation and implementation of the cyclooxygenase reaction [106]. The action of various agonists, toxic agents and carcinogens (PMA, high concentration of glucose, angiotensin II, 2-aminobiphenyl, to name a few) enhance expression of inducible COX-2, and the level of expression depends upon ROS, which in turn is determined by activity of NADPH-oxidases $[107,108]$. The question of whether there is feedback remains unresolved: although it has been demonstrated that the level of COX-2 expression has no influence on the level of ROS [109], an early paper presented indirect evidence of such an effect [110]. If COX-2 is considered as a relevant source of free oxygen radicals, inhibiting the activity of this enzyme would reduce oxidative stress. Indeed, there is evidence to indicate that selective and timely use of COX-2 inhibitors (nimesulide or celecoxib) would be useful in preventing the onset and development of atherosclerosis by enhancing antioxidant defense system (SOD, GPx, and total antioxidant status (TAS)) [111]. Aspirin is known to reduce the incidence and mortality from ischemic heart disease and is a mainstay in the prevention of vascular complications of atherosclerosis. On the other hand, during the last decade it has been suggested that nonsteroidal anti-inflammatory drugs (NSAIDs), and in particular inhibitors of COX-2, are associated with an increase in cardiovascular morbidity and mortality. It has been shown recently that COX-1 but not COX-2 drives vascular prostacyclin in the healthy cardiovascular system; COX-2 profoundly limits atherosclerosis, and this protection is independent of local prostacyclin release [112]. Moreover, selective depletion of COX-2 in vascular smooth muscle cells and endothelial cells depressed biosynthesis of PGI2 and PGE2, elevated 
blood pressure, and accelerated atherogenesis in Ldlr knockout mice [113]. Deletion of COX-2 in vascular smooth muscle cells and endothelial cells coincided with an increase in COX-2 expression in lesional macrophages and increased biosynthesis of thromboxane [113]. To reconcile the differences, a special experiment was recently conducted to show that low dose aspirin indeed reduces early atherosclerosis, while inhibition of COX-2 by meloxicam (which is also known as a potential vasculitis inducer) had a null effect on the extent of atherosclerosis in ApoE knockout mice [114]. Thus, the COX-2/ROS relations are presently in the background scene; the perspective could be the targeted delivery of COX-2 inhibitors to macrophages, which may conserve their efficacy while limiting cardiovascular risk. In any case, it now seems now that COX per se cannot serve as a source of pathogenic ROS.

At the same time, growing evidence suggests that lipoxygenases (LO) and COX-generated arachidonic acid metabolites can induce ROS generation by stimulating NOX and that a potential signaling connection exits between the LOX/COX metabolites and NOX [115]. Lipoxygenases (EC 1.13.11.-) are a family of iron-containing enzymes that catalyse the dioxygenation of polyunsaturated fatty acids in lipids containing a cis,cis-1,4-pentadiene structure. In mammals, a number of lipoxygenases isozymes are involved in the metabolism of eicosanoids: arachidonate 12lipoxygenase (12-LO, EC 1.13.11.31), arachidonate 5-lipoxygenase (5-LO, EC 1.13.11.34), erythroid cell-specific 15-lipoxygenase (EC 1.13.11.33). 5-Lipoxygenase (5-LO) is the key enzyme involved in the synthesis of proinflammatory leukotrienes (LTs) [116]. The pathophysiological effects of LTs can be modulated by the selective inhibition of 5-LO and, in the last decade, significant research efforts have led to the exploitation of 5-LO pathway for developing new drugs against inflammatory diseases. In particular, attention is focused on the contribution of leukotriene B4 (LTB4), a potent bioactive eicosanoid that is derived from 5-LOX, and its receptors, BLT1 and BLT2, to NOX stimulation through a signaling mechanism that leads to ROS generation [115, 117]. Some flavonoids known as antioxidants (e.g. genistein) when taken in excess may possesses a pro-oxidant potential, and surprisingly it was demonstrated that increased generation of ROS was induced with inhibited expression of NOX4 and COX1/2 as well as increased activity of the glutathione redox system [118]. The cellular expression of 5-LO, however, was up-regulated and the addition of 5-LO inhibitor (Zileuton) decreased genistein-induced intracellular ROS level, close to that obtained following the addition of the ROS scavenger N-acetylcysteine. Besides 5-LO, proinflammatory cytokine stimulation induces 12-lipoxygenase (12-LO) expression in human islet beta cells; 12hydroxyeicosatetraenoic acid (12-HETE), a product of 12-LO activity, stimulated NOX1 expression in human islets and production of ROS [119]. 15-LO plays a role in atherogenesis. 15(S)-hydroxyeicosatetraenoic acid [15(S)HETE], the major 15-LO-dependent metabolite of arachidonic acid, stimulated the production of ROS by monocytes through the xanthine oxidase-mediated activation of NOX [120]. ROS production led to the Syk-, Pyk2-, and 
MAPK-dependent production of the proinflammatory cytokine IL-17A in a manner that required the transcription factor CREB (cyclic adenosine monophosphate response element-binding protein). In addition, this pathway was required for the 15(S)-HETE-dependent migration and adhesion of monocytes to endothelial cells. Moreover, peritoneal macrophages from ApoE-/- mice fed a high-fat diet, when compared to those from similarly fed ApoE-/:12/15-LO-/- mice, exhibited increased: xanthine oxidase and NOX activities; ROS production; phosphorylation of Syk, Pyk2, MAPK and CREB; and IL-17A production. These events correlated with increased lipid deposits and numbers of monocytes and macrophages in the aortic arches of ApoE-/- mice, which resulted in atherosclerotic plaque formation [120].

\section{Hemoglobin and Red Blood Cells}

Hemoglobin $(\mathrm{Hb})$ is the iron-containing oxygen-transport metalloprotein in red blood cells of all vertebrates (with the exception of the fish family Channichthyidae [121]) as well as the tissues of some invertebrates. In mammals, Hb makes up about $96 \%$ of red blood cells' dry content (by weight), and around 35\% of the total content (including water) [122]. The mammalian Hb molecule is an assembly of four globular protein subunits, and each subunit is composed of a protein chain tightly associated with a non-protein heme group. Heme is the archetypical $\mathrm{O}_{2}$ binding molecule, a member of the porphyrin family composed of four pyrrole rings bound to a central iron atom, which can be converted from ferrous $\left(\mathrm{Fe}^{2+}\right)$ to ferric $\left(\mathrm{Fe}^{3+}\right)$ by binding of molecular $\mathrm{O}_{2}$ [123]. The ability of heme to bind $\mathrm{O}_{2}$ reversibly has long been of interest in terms of $\mathrm{O}_{2}$ sensing $[123,124,125]$. Heme proteins implicated in $\mathrm{O}_{2}$ sensing include mitochondrial cytochromes, NADPH oxidase, cytochrome P-450, NOS, guanylate cyclase, catalase, cystathionine $\beta$-synthase, and heme oxygenase; some of these were discussed above in relation to ROS generation. Heme itself is a pro-oxidant [126 ].

Red blood cells (RBC) are continuously exposed to both endogenous and exogenous sources of ROS. Endogenous ROS are continuously generated by the slow autoxidation of Hb [127]. The initial oxidative process in $\mathrm{Hb}$ involves the spontaneous oxidation of its ferrous iron, known as autoxidation of Hb, leading to non-functional metHb and superoxide anion. Moreover, $\mathrm{H}_{2} \mathrm{O}_{2}$ arising from $\mathrm{O}_{2}{ }^{-}$dismutation could react with $\mathrm{Hb}$, either ferrous or ferric, forming ferrylHb $\left(\mathrm{Fe}^{4+}\right)$ or ferryl protein radicals, respectively. Finally, the formation of ferrylHb could also result in the formation of heme degradation products [21]. FerrylHb, but not haemoglobin or metHb, induce the expression of proinflammatory genes in endothelial cells in vitro and the recruitment of polymorphonuclear cells (PMNs) in vivo [128]. In hypoxia and some other conditions Hb is not fully oxygenated, and there is a dramatic increase in the rate of $\mathrm{Hb}$ autoxidation for this partially oxygenated $\mathrm{Hb}$ [129]. Of particular importance is an increase in the affinity of partially oxygenated $\mathrm{Hb}$ for the RBC membrane [130]; this limits the efficiency of the 
antioxidant system, which is primarily cytosolic, from neutralizing the ROS formed at the membrane. The pool of un-neutralized ROS in the RBC has been shown to damage the RBC membrane [131] and to be transferred to other cells coming into contact with RBC, resulting in tissue damage and inflammation [132; 133]. The ROS generated on the $\mathrm{RBC}$ membrane through $\mathrm{Hb}$ autoxidation are ideally located to react with membrane lipids and proteins producing lipid peroxidation and modified membrane proteins that can affect the membrane structure [21]. Although exogenous ROS has been shown to cause lipid peroxidation, this lipid oxidative damage does not affect RBC deformability [134]. Damage to membrane proteins is, thus, presumably responsible for the impaired cellular deformability associated with oxidative stress. The role of protein damage in producing impaired deformability is consistent with a dominant role for the membrane cytoskeleton in regulating RBC deformability $[135,136,137]$.

The contribution of oxidative stress that does not necessarily involve $\mathrm{Hb}$ autoxidation to deformability is indicated by caspase-3, which is activated in the RBC by oxidative reactions and has been shown to partially degrade band 3 . This affects interactions of band 3 with cytosolic proteins as well as the linkage to ankyrin and the cytoskeleton, which finally induces exposure of phosphatidylserine (PS) to the outer surface [138, 1339, 140]. This dramatic rearrangement of the membrane has been shown to involve a concomitant decrease in deformability [141, 142]. In addition, oxidative stress has been shown to inhibit Ca-ATPase [143], and enhanced intracellular calcium can affect deformability by activation of the Gardos channel resulting in leakage of $\mathrm{K}^{+}$from the RBC [144] causing shrinkage of the cells and impaired deformability $[141,145]$. An increase in intracellular calcium also activates calpain, transglutaminase-2 and some other caspases that can degrade/crosslink cytoskeleton proteins [146]. It also inhibits phosphotyrosine phosphatase increasing band 3 phosphorylation [147].

RBC-derived iron-rich heme group is one of the main sources of oxidative stress, leading to progression of chronic pathological vascular remodeling [148]. Lysis of RBC within the intraluminal thrombus of abdominal aortic aneurysm or inside the plaque associated with haemorrhage due to microvessel rupture or with RBC extravasation in initial plaques, may lead to subsequent release of the pro-oxidant $\mathrm{Hb}$, that when oxidized in mtHb, liberates heme and iron within tissue and transfers them to lipoproteins [149]. The presence of these oxidized forms of Hb in ruptured advanced atherosclerotic plaques has been observed [150]. The authors demonstrated that exposure of RBC to lipids from atherosclerotic lesions causes haemolysis and oxidation of $\mathrm{Hb}$, and conversely, $\mathrm{Hb}$ promoted further lipid oxidation. In contrast, Boyle et al. reported that erythrocytes, $\mathrm{Hb}$ and heme, released by intraplaque haemorraghe, stimulated cholesterol efflux and decrease oxidative stress in macrophages [151]. Similarly, Finn et al. reported that haemoglobin/haptoglobin stimulated macrophages expressed more ferroportin, had less intracellular iron and ROS production and were more resistant to cholesterol loading due to upregulation of the ATP-binding cassette transporter [152]. Two peaks were identified by mass spectrometric analysis corresponding to alpha and 
beta chains of $\mathrm{Hb}$ associated with proinflammatory high-density lipoprotein (HDL). HDL-associated Hb is predominantly in the oxygenated (oxyHb) form with distinct physical and chemical properties. Furthermore, oxyHbcontaining proinflammatory HDL potently consumed NO and contracted arterial vessels ex vivo [153]. Apart from the oxidative toxicity of $\mathrm{Hb}$, it is a potent scavenger of $\mathrm{NO}$ - a critical regulator of vascular tone, endothelial function and thrombosis. Hb functions as an allosterically and redox-regulated nitrite reductase whose "enzyme activity” couples hypoxia to increased NO-dependent blood flow [154]. Hb potently inactivates the NO radical forming nitrate and metHb, producing endothelial dysfunction under haemolytic conditions [155]. Free heme can threaten vascular endothelial cell integrity through oxidative modification of low-density lipoproteins (oxLDLs) [156]. Initially, most of this oxLDL is contained within foam cell lysosomes primarily in the form of the peroxidised lipid-protein complex ceroid [157]. Specifically, ceroids are insoluble sudanophilic polymers of oxidised cholesterol and proteins; they are hallmarks of atherothrombotic pathology [158]. Development of ceroids could colocalise with iron deposits within cell and tissue [159], and presence of Hb and MPO has been identified in ceroids [160]. Similarly, ceroids can be found in intraluminal thrombus of abdominal aortic aneurysm [149]. These data also provide evidence of the role played by heme-derived iron in the genesis of tissue oxidative process, modifying both lipids and proteins. Iron is an essential element that plays crucial roles in cell proliferation and metabolism by serving as a functional constituent of various enzymes. However, when present in excess, free iron generates ROS, e.g. via the Fenton reaction. In this respect, another iron species named non-transferrin bound iron seem to play an important role in the ROS-induced toxicity both at the cell membrane but also intracellularly [161]. Conversely, ROS themselves can modulate iron homeostasis as a defense mechanism against iron-induced oxidative stress, since the expression of many genes involved in iron transport and storage is regulated by ROS [162]. Human carotid atherosclerotic lesions contain 3- to 17-fold more iron than healthy control arteries [163]. Iron can mediate both lipid and protein oxidation. However, it has been suggested that elevated levels of iron contribute to the extent of protein, but not lipid, oxidation in advanced human atherosclerotic lesions [164]. The source of redox-active iron in vascular tissue could involve both RBC lysis and erythrophagocytosis. Most of the iron within vascular lesions is associated with phagocytes [165]. The storage and processing of iron from erythrophagocytosis or other sources within vascular lesions could have an important role in disease initiation and progression.

\section{Conclusion: ROS, atherosclerosis and some related points of research}

In the vasculature, reactive oxygen species (ROS) generated by both mitochondrial respiration and enzymatic sources serve as integral components of cellular signaling and homeostatic mechanisms. Because ROS are highly reactive biomolecules, the cellular redox milieu is carefully maintained by small-molecule antioxidants and antioxidant enzymes to prevent the deleterious consequences of ROS excess. When this redox balance is 
perturbed, because of either increased ROS production or decreased antioxidant capacity, oxidant stress is increased in the vessel wall and, if not offset, vascular dysfunction ensues. A number of heritable polymorphisms of prooxidant enzymes, including 5-LO, COX-2, eNOS, and NOX, have been identified and found to modulate ROS production and, thereby, the risk of atherothrombotic cardiovascular disease in individuals with these genetic polymorphisms [166]. Similarly, heritable deficiency of the antioxidant enzymes catalase, GPx, glutathione-Stransferases, heme oxygenase and glucose-6-phosphate dehydrogenase favors ROS accumulation, and has been associated with an increased risk of vascular disease. The scope of this review was to examine several possible sources of ROS as risk factors for atherosclerosis. According to literature, NOX may play a central role in development of various vascular diseases, they are considered as a source of "kindling radicals" affecting other enzymes [15]. Thus, elevated activity of NOX1 in SMC results in uncoupling of eNOS and converting XOR to xanthine oxidase, thus making them additional sources of superoxide [28, 29]. In the atherosclerotic plaque, XOmediated ROS formation is pro-inflammatory [71]. The uncoupled eNOS can simultaneously produce NO and O2-, they react to generate peroxinitrite, which is another uncoupler of NOS [85].

Calcium-dependent NOX5 has been implicated in oxidative damage in human atherosclerosis, whereas NOX4 may have a role in protecting the vasculature [15]. CYP-generated ROS can also play a dual role in development of atherosclerosis and vascular tone, inducing pro-inflammatory effects through expression of addressin genes and adhesion molecules [78], though generating EDHF in certain conditions [82].

Nox2 and p22phox proteins were elevated throughout lesion development [50]. In phagosomes, superoxide generated by NOX2 interacts with chloride ions under catalytic control of MPO, with production of hypochlorite [30]. Serum MPO levels were correlated with restenosis and atherosclerotic lesions [92]. Activation of the lipoxygenase and cyclooxygenase signaling pathways is also coupled with activation of NOX2 [31, 32, 108, 109]. COX and evidently LO per se cannot serve as a source of pathogenic ROS, though their expression and/or activity can be affected by ROS. Reciprocally, LO- and COX-generated arachidonic acid metabolites can induce ROS generation by stimulating NOX $[115,118]$.

Mitochondrial ROS of endothelial cells and lesional macrophages contribute to initiation of inflammatory reactions via NFkB to recruit leukocytes into the intima, and successive oxidative burst in activated neutrophils can exceed the initial generation of ROS [60, 61, 62]. Endothelial cells and especially leucocytes can damage RBC, though in hypoxic conditions RBC can independently generate ROS due to autoxidation of Hb. Oxidative damage to RBC membrane proteins is responsible for the impaired cellular deformability [134]. Elevated levels of iron contribute to the extent of protein, but not lipid, oxidation in advanced human atherosclerotic lesions [164]. The source of redox-active iron in vascular tissue could involve both RBC lysis and erythrophagocytosis [165]. 
The relations between different resources of ROS and atherosclerosis are summarized in Figure 1.

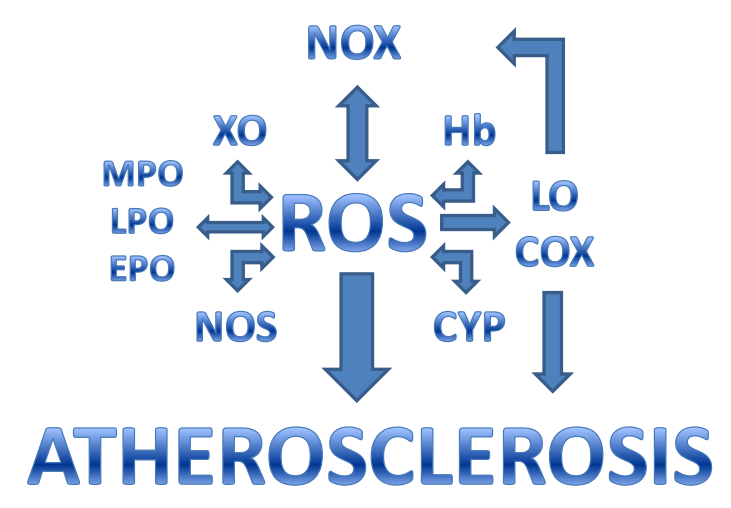

Figure 1. Contribution of various sources of ROS in development of atherosclerosis.

ROS play a critical role in vascular tone and disease. A break in integrity of endothelium can be induced by ROS effects on the key enzymes of metabolism [166, 167], as well as on different signaling and effector pathways, i.e. receptors of plasma membrane, kinases and phosphatases, transcriptional factors and their interaction with DNA, translation, processing and secretion of integrins and adhesion proteins, cytoskeleton and its interaction with plasma membrane $[4,80]$. The levels of oxidative stress have been implicated in the pathogenesis associated with cancer, hypertension and atherosclerosis [168]. Among the functional effects of ROS are: metabolic control in cells [169]; regulation of HIF-1 $\alpha$ in hypoxia [170, 171]; triggering of autophagy through a cysteine protease Atg4 [172]; formation of inflammasome NLRP3; and launch of inflammation [173, 174, 175]. ROS mediate effects of proinflammatory cytokines (TNF-alpha, IFN-gamma, IL-1) and are considered to be atherogenic factors [176, 177, $178,179]$. On the other hand, proapoptotic oxidative or endoplasmic reticulum stress inducers trigger another stress reaction in macrophages, autophagy, which becomes dysfunctional in atherosclerosis and its deficiency promotes atherosclerosis in part through inflammasome hyperactivation. Inhibition of autophagy by silencing ATG5 or other autophagy mediators enhances apoptosis and NOX-mediated oxidative stress while at the same time rendering the apoptotic cells less well recognized by efferocytes [180, 181].

Having a strategic position between blood and tissues, the endothelium controls hemostasis perfusion, inflammation, and recruitment of inflammatory cells; on the other hand, an increased level of ROS can damage endothelium and enhance expression of proinflammatory genes [182, 183]. Superoxide anion generated by monocytes/macrophages in oxidative burst is considered to be the principal source of atherosclerosis [184, 185, 
186]. OxLDL induce expression of adhesion molecules ICAM-1, VCAM-1, and E-selectin, enhancing adhesion of monocytes to endothelial cells and foam cells formation, and leading to cytotoxicity, inflammation and atherosclerotic lesions [187, 188, 189]. ROS also induce secretion of Weibel-Palade bodies (WPB) from endothelial cells [190, 191]. A similar effect coupled with elevated expression of P-selectin is induced by activated platelets [192]. P-selectin of platelets and endothelial cells, and E-selectin of endothelial cells, serve as receptors of leukocytes that recognize specific epitopes on the surface of neutrophils and monocytes [192, 193]. The level of Pselectin in blood is tightly correlated with probability of a lethal outcome for atherosclerotic patients [194]. The WPB are widely known to be reservoirs of van Willebrand factor (VWF); along with VWF and P-selectin, these unique organelles of endothelial cells secrete VWF-propolypeptide (proregion), endothelin-1, angiopoietin-2, interleukin-8 and eotaxin-3 (attractants for neutrophils and eosiniphils, respectively), CD63 antigen and some other substances [195, 196, 197, 198, 199, 200]. It should be noted here that extracellular inducers of WPB excretion are vasoactive agonists thrombin and histamine [198, 201]. It has been revealed that thrombin causes a two-phase elevation of ROS in endothelial cells (in 15 min and $3 \mathrm{~h}$ ), accompanied by increased expression of mRNA subunit p22 ${ }^{\text {phox }} \cdot \mathrm{H}_{2} \mathrm{O}_{2}$ causes a similar effect, whereas vitamin $\mathrm{C}$ and diphenyleneiodonium (DPI) prevents it. The effect of thrombin is mediated by p38 MAP-kinase and PI3K/Akt. The positive feedback mechanism consists of induction of a small quantity of ROS through NOX with further expression of p22 phox and synthesis of a significant amount of ROS [201]. Also, ROS mediate the angiotensin II (AII)-induced dysfunction of endothelial cells. AII triggers translocation of Nox2 to endothelial plasma membrane and its association with adenosine receptor A2A; simultaneously, phosphorylation of p47phox ERK1/2, p38 MAPK and Akt is observed, with further production of ROS and reduction of endothelium-dependent relaxation in response to acetylcholine [202]. SCH58261, an antagonist of A2AR, decreases production of ROS and retains reaction to acetylcholine. Redox regulation of vascular NOXs activation provides both negative feedback and feed-forward regulation mechanisms. For example, Rac1 protein turnover is strongly dependent on the redox status of the cell, creating a negative feedback mechanism [203]. At the same time, a feed-forward mechanism exists, by which exogenous exposure of SMC or fibroblasts to H2O2-activated NOX stimulates them to produce endogenous superoxide anion, thereby amplifying the vascular injury process [204]. The self-limiting mechanism could predominate during physiological conditions, and be involved in maintaining low output of a non-phagocyte NOX, whereas the feed-forward mechanism may have a role in the NOX-dependent oxidative stress in a variety of diseases, including atherosclerosis [15].

It can be readily seen from these and many other data obtained recently that there are tight relations between ROS generation and vascular functions in the normal physiological state (signaling) and various pathologies, atherosclerosis being among them. Unfortunately, there are no embracing studies on interrelations, 
feedback and feed-forward regulation mechanisms of different sources of ROS generation, described in this review, in development of atherosclerosis and other vascular pathologies. Discovery of these relations constitute a genuine challenge and would require great endeavor.

A better mechanistic understanding of mechanisms of ROS production and effects, their balance in normal state and imbalance in atherosclerosis, their control by enzymatic and non-enzymatic defense mechanisms, and their feedback and feed-forward regulation mechanisms may lead to more effective prophylactic and/or therapeutic strategies.

\section{Acknowledgements}

This work has been supported by the Russian Foundation for Basic Research Grants \#\#14-04-00951, 13-04-01728, and the Russian Scientific Foundation Grant \#14-15-01004. 


\section{References}

[1] Baldrige CW, Gerard RW. The extra respiration of phagocytosis. AJP - Legacy 1932; 103: 235-6.

[2] Vara D, Pula G. Reactive Oxygen Species: Physiological Roles in the Regulation of Vascular Cells. Curr Mol Med. 2014. Jun 3. [Epub ahead of print].

[3] Shappell SB, Toman C, Anderson DC, et al. Mac-1 (CD11b/CD18) mediates adherence-dependent hydrogen peroxide production by human and canine neutrophils. J Immunol 1990; 144(7): 2702-11.

[4] Jones DP. Radical-free biology of oxidative stress. Am J Physiol Cell Physiol 2008; 295 (4), C849-8.

[5] Liu H, Colavitti R, Rovira II, Finkel T. Redox-dependent transcriptional regulation. Circ Res. 2005; 97: 967-74.

[6] Magder S. Reactive oxygen species: toxic molecules or spark of life? Crit Care. 2006; 10: 208.

[7] Janero DR, Hreniuk D. Suppression of TCA cycle activity in the cardiac muscle cell by hydroperoxide-induced oxidant stress. Am J Physiol 1996; 270 (6 Pt 1), C1735-42.

[8] Lubrano V, Balzan S. LOX-1 and ROS, inseparable factors in the process of endothelial damage. Free Radic Res. 2014 Jun 23:1-8. [Epub ahead of print]].

[9] Thannickal VJ, Fanburg BL. Reactive oxygen species in cell signaling. Am J Physiol Lung Cell Mol Physiol 2000; 279(6): L1005-28.

[10] Petry A, Weitnauer M, Görlach A. Receptor activation of NADPH oxidases. Antioxid Redox Signal 2010; 13(4): 467-87.

[11] Miller EW, Dickinson BC, Chang CJ. Aquaporin-3 mediates hydrogen peroxide uptake to regulate downstream intracellular signaling. Proc Natl Acad Sci USA 2010; 107: 15681-6.

[12] Proctor P. Electron-transfer factors in psychosis and dyskinesia. Physiol Chem Phys 1972; 4 (4): 349-60.

[13] Proctor P, Reynolds E. Free radicals and disease in man. Physiol Chem and Phys Med NMR 1984; 16(3): 175-95.

[14] Lambeth JD. NOX enzymes and the biology of reactive oxygen. Nat Rev Immunol 2004; 4(3): 181-89.

[15] Konior A, Schramm A, Czesnikiewicz-Guzik M, Guzik TJ. NADPH oxidases in vascular pathology. Antioxid Redox Signal 2014; 20(17): 2794-814.

[16] Muzykantov VR, Sakharov DV, Domogatsky SP, Goncharov NV, Danilov SM. Directed targeting of immunoerythrocytes provides local protection of endothelial cells from damage by hydrogen peroxide. Am J Pathol 1987; 128(2): 276-85. 
[17] Zaki ME, El-Bassyouni H, Kamal S, et al. Association of serum paraoxonase enzyme activity and oxidative stress markers with dyslipidemia in obese adolescents. Indian J Endocrinol Metab 2014; 18(3): 340-4.

[18] Kragh-Hansen U. Molecular and practical aspects of the enzymatic properties of human serum albumin and of albumin-ligand complexes. Biochim Biophys Acta. 2013; 1830(12): 5535-44.

[19] Lau D, Baldus S. Myeloperoxidase and its contributory role in inflammatory vascular disease. Pharmacol Ther. 2006; 111: 16-26.

[20] White CR, Darley-Usmar V, Berrington WR, et al. Circulating plasma xanthine oxidase contributes to vascular dysfunction in hypercholesterolemic rabbits. Proc Natl Acad of Sci USA 1996; 93: 8745-9.

[21] Mohanty JG, Nagababu E, Rifkind JM. Red blood cell oxidative stress impairs oxygen delivery and induces red blood cell aging. Front Physiol 2014; 5: 84.

[22] Drummond GR, Selemidis S, Griendling KK, Sobey CG. Combating oxidative stress in vascular disease: NADPH oxidases as therapeutic targets. Nat Rev Drug Discov. 2011; 10(6): 453-71.

[23] Segal AW. How neutrophils kill microbes. Annu Rev Immunol. 2005; 23: 197-223.

[24] Hilenski LL, Clempus RE, Quinn MT, et al. Distinct subcellular localizations of Nox1 and Nox4 in vascular smooth muscle cells. Arterioscler Thromb Vasc Biol 2004; 24: 677-83.

[25] Gavazzi G, Banfi B, Deffert C, et al. Decreased blood pressure in NOX1-deficient mice. FEBS Lett. 2006; 580: 497-504.

[26] Matsuno K, Yamada H., Iwata K, et al. Nox1 is involved in angiotensin II-mediated hypertension: a study in Nox1-deficient mice. Circulation 2005; 112: 2677-85.

[27] Garrido AM, Griendling KK. NADPH oxidases and angiotensin II receptor signaling. Mol Cell Endocrinol 2009; 302: 148-58.

[28] Dikalova AE, Góngora MC, Harrison DG, et al. Upregulation of Nox1 in vascular smooth muscle leads to impaired endothelium-dependent relaxation via eNOS uncoupling. Am J Physiol Heart Circ Physiol 2010; 299(3): H673-9

[29] McNally JS, Davis ME, Giddens DP, et al. Role of xanthine oxidoreductase and NAD(P)H oxidase in endothelial superoxide production in response to oscillatory shear stress. Am J Physiol Heart Circ Physiol. 2003; 285: H2290-7.

[30] Faurschou M., Borregaard N. Neutrophil granules and secretory vesicles in inflammation. Microbes Infect 2003; 5: 1317-1327 
[31] Ha YJ, Seul HJ, Lee JR. Ligation of CD40 receptor in human B lymphocytes triggers the 5-lipoxygenase pathway to produce reactive oxygen species and activate p38 MAPK. Exp Mol Med 2011; 28; 43(2): 101-10.

[32] Xia M, Li G, Ma J, Ling W. Phosphoinositide 3-kinase mediates CD40 ligand-induced oxidative stress and endothelial dysfunction via Rac1 and NADPH oxidase 2. J Thromb Haemost 2010 Feb; 8(2): 397-406.

[33] Bhogal RH, Weston CJ, Curbishley SM, et al. Activation of CD40 with platelet derived CD154 promotes reactive oxygen species dependent death of human hepatocytes during hypoxia and reoxygenation. PLoS One. 2012; 7(1): e30867.

[34] Yang L, Zhang J, Yan C, et al. Expression Induced by TNF- $\alpha$ via NF-кB Pathway in Endothelial Cells. Cell Physiol Biochem. 2012; 30(5): 1287-98.

[35] Youn JY, Gao L, Cai H. The p47phox- and NADPH oxidase organiser 1 (NOXO1)-dependent activation of NADPH oxidase 1 (NOX1) mediates endothelial nitric oxide synthase (eNOS) uncoupling and endothelial dysfunction in a streptozotocin-induced murine model of diabetes. Diabetologia 2012; 55(7): 2069-79.

[36] Sumimoto H. 2008. Structure, regulation and evolution of Nox-family NADPH oxidases that produce reactive oxygen species. FEBS J; 275: 3249-3277

[37] Kuroda J, Nakagawa K, Yamasaki T, et al. The superoxide-producing NAD(P)H oxidase Nox4 in the nucleus of human vascular endothelial cells. Genes Cells 2005; 10: 1139-51.

[38] Brown DI, Griendling KK . Nox proteins in signal transduction. Free Radic Biol Med 2009; 47; 1239-53.

[39] Clempus RE, Sorescu D, Dikalova AE, et al. Nox4 is required for maintenance of the differentiated vascular smooth muscle cell phenotype. Arterioscler Thromb Vasc Biol. 2007; 27: 42-8.

[40] Lee Y.M., Kim B.J., Chun Y.S., et al. NOX4 as an oxygen sensor to regulate TASK-1 activity. Cell Signal 2006; 18:499-507.

[41] Sylvester JT, Shimoda LA, Aaronson PI, Ward JP. Hypoxic pulmonary vasoconstriction. Physiol. Rev. 2012; 92: 367-520.

[42] Martyn KD, Frederick LM, von Loehneysen K, et al. Functional analysis of Nox4 reveals unique characteristics compared to other NADPH oxidases. Cell Signal 2006; 18(1): 69-82.

[43] Helmcke I, Heumüller S, Tikkanen R, et al. Identification of structural elements in Nox1 and Nox4 controlling localization and activity. Antioxid Redox Signal. 2009; 11(6):1279-87.

[44] Mahadev K, Motoshima H., Wu X, et al. The NAD(P)H oxidase homolog Nox4 modulates insulinstimulated generation of $\mathrm{H}_{2} \mathrm{O}_{2}$ and plays an integral role in insulin signal transduction. Mol Cell Biol 2004; 24: 1844-54. 
[45] Ben Mkaddem S, Pedruzzi E, Werts C, et al. Heat shock protein gp96 and NAD(P)H oxidase 4 play key roles in Toll-like receptor 4-activated apoptosis during renal ischemia/reperfusion injury. Cell Death Differ. 2010; 17(9): 1474-85.

[46] Suzuki Y, Hattori K, Hamanaka J, et al. Pharmacological inhibition of TLR4-NOX4 signal protects against neuronal death in transient focal ischemia. Sci Rep. 2012; 2: 896.

[47] Sturrock A, Cahill B, Norman K, et al. Transforming growth factor \{beta 1 induces Nox 4 NAD(P)H oxidase and reactive oxygen species-dependent proliferation in human pulmonary artery smooth muscle cells. Am J Physiol Lung Cell Mol Physiol 2006; 290(4): L661-73.

[48] Hu T, Ramachandrarao SP, Siva S, et al. Reactive oxygen species production via NADPH oxidase mediates TGF-beta-induced cytoskeletal alterations in endothelial cells. Am J Physiol Renal Physiol 2005; 289: F816-825.

[49] Pedruzzi E, Guichard C, Ollivier V, et al. NAD(P)H oxidase Nox-4 mediates 7-ketocholesterol-induced endoplasmic reticulum stress and apoptosis in human aortic smooth muscle cells. Mol Cell Biol 2004; 24: 10703-17.

[50] Xu S, Chamseddine AH, Carrell S, Miller FJ Jr. Nox4 NADPH oxidase contributes to smooth muscle cell phenotypes associated with unstable atherosclerotic plaques. Redox Biol 2014; 2: 642-50/

[51] Geiszt M, Witta J, Baffi J, et al. 2003. Dual oxidases represent novel hydrogen peroxide sources supporting mucosal surface host defense. FASEB J. 2003; 17: 1502-04.

[52] Ris-Stalpers C. Physiology and pathophysiology of the DUOXes. Antioxid Redox Signal 2006; 8(9-10): $1563-72 /$

[53] Yoshihara A, Hara T, Kawashima A, et al. Regulation of dual oxidase expression and $\mathrm{H} 2 \mathrm{O} 2$ production by thyroglobulin. Thyroid. 2012; 22(10): 1054-62.

[54] Ohye H, Sugawara M. Dual oxidase, hydrogen peroxide and thyroid diseases. Exp Biol Med (Maywood). 2010; 235(4): 424-33.

[55] Kilic ID, Tanriverdi H, Fenkci S, et al. Noninvasive indicators of atherosclerosis in subclinical hypothyroidism. Indian J Endocrinol Metab. 2013; 17(2): 271-5.

[56] Wang P, Xu TY, Guan YF, et al. Vascular smooth muscle cell apoptosis is an early trigger for hypothyroid atherosclerosis. Cardiovasc Res 2014; 102(3): 448-59.

[57] Giorgio M, Migliaccio E, Orsini F, et al. Electron transfer between cytochrome c and p66Shc generates reactive oxygen species that trigger mitochondrial apoptosis. Cell 2005; 122: 221-33. 
[58] Brand MD. The sites and topology of mitochondrial superoxide production. Exp Gerontol 2010; 45: 46672.

[59] Wang Y, Tabas I. Emerging Roles of Mitochondria ROS in Atherosclerotic Lesions: Causation or Association? J Atheroscler Thromb. 2014 27; 21(5): 381-90.

[60] Pamukcu B, Lip GY, Shantsila E. The nuclear factor-kappa B pathway in atherosclerosis: a potential therapeutic target for atherothrombotic vascular disease. Thromb Res 2011; 128(2): 117-23.

[61] Tsukimori K, Fukushima K, Tsushima A, Nakano H. Generation of reactive oxygen species by neutrophils and endothelial cell injury in normal and preeclamptic pregnancies. Hypertension 2005; 46(4): 696-700.

[62] Wang Y, Wang GZ, Rabinovitch PS, Tabas I. Macrophage mitochondrial oxidative stress promotes atherosclerosis and nuclear factor-kB-mediated inflammation in macrophages. Circ Res. 2014; 114(3): 421-33.

[63] Boueiz A. Hassoun PM. Regulation of endothelial barrier function by reactive oxygen and nitrogen species. Microvasc Res 2009; 77: 26-34.

[64] Huppert J. Closhen D. Croxford A., et al. Cellular mechanisms of IL-17-induced blood-brain barrier disruption. FASEB J 2010; 24: 1023-34.

[65] Yu E. Mitochondrial DNA Damage can Promote Atherosclerosis Independently of Reactive Oxygen Species and Correlates with Higher Risk Plaques in Humans. Heart. 2014; 100 (Suppl 3): A128-9.

[66] Waud WR, Rajagopalan KV. The mechanism of conversion of rat liver xanthine dehydrogenase from an NAD+-dependent form (type D) to an $\mathrm{O}_{2}$-dependent form (type O). Arch Biochem Biophys 1976; 172: 365-79.

[67] Amaya Y, Yamazaki K, Sato M, Noda K, Nishino T. Proteolytic conversion of xanthine dehydrogenase from the NAD-dependent type to the $\mathrm{O}_{2}$-dependent type. Amino acid sequence of rat liver xanthine dehydrogenase and identification of the cleavage sites of the enzyme protein during irreversible conversion by trypsin. J Biol Chem 1990; 265:14170-5.

[68] Harris CM, Massey V. The reaction of reduced xanthine dehydrogenase with molecular oxygen. Reaction kinetics and measurement of superoxide radical. J Biol Chem. 1997; 272: 8370-9.

[69] Enroth C, Eger BT, Okamoto K, Nishino T, Pai EF. Crystal structures of bovine milk xanthine dehydrogenase and xanthine oxidase: structure-based mechanism of conversion. Proc Natl Acad Sci USA. 2000; 97: 10723-8.

[70] Czupryna J, Tsourkas A. Xanthine oxidase-generated hydrogen peroxide is a consequence, not a mediator of cell death. EBS J. 2012; 279(5): 844-55. 
[71] Nomura J, Busso N, Ives A, et al. Xanthine oxidase inhibition by febuxostat attenuates experimental atherosclerosis in mice. Sci Rep. 2014 Apr 1; 4: 4554.

[72] Houston M, Estevez A, Chumley P, et al. Binding of xanthine oxidase to vascular endothelium. Kinetic characterization and oxidative impairment of nitric oxide-dependent signaling. J Biol Chem 1999; 274(8): 498594.

[73] Malik UZ, Hundley NJ, Romero G, Radi R, et al. Febuxostat inhibition of endothelial-bound XO: implications for targeting vascular ROS production. Free Radic Biol Med 2011; 51(1): 179-84.

[74] Fleming I. Cytochrome P450 enzymes in vascular homeostasis. Circ Res 2001; 89: 753-62.

[75] Fisslthaler B, Michaelis UR, Randriamboavonjy V, Busse R, Fleming I. Cytochrome p450 epoxygenases and vascular tone: novel role for HMG-CoA reductase inhibitors in the regulation of CYP2C expression. Biochim Biophys Acta 2003; 1619: 332-9.

[76] Fleming I, Michaelis UR, Bredenkötter D, et al. Endothelium-derived hyperpolarizing factor synthase (cytochrome p450 2C9) is a functionally significant source of reactive oxygen species in coronary artery. Circ Res 2001; 88: 44-51.

[77] Fichtlscherer S, Dimmeler S, Breuer S, et al. Inhibition of cytochrome p450 2C9 improves endotheliumdependent, nitric oxide-mediated vasodilatation in patients with coronary artery disease. Circulation 2004; 109: 178-83.

[78] Sasaki M, Ostanin D, Elrod JW, et al. TNF- $\alpha$-induced endothelial cell adhesion molecule expression is cytochrome p-450 monooxygenase dependent. Am J Physiol Cell Physiol 20003; 284: C422-8.

[79] Chen X, Andresen1 BT, Hill M, Zhang J, Booth F, Zhang C. Role of Reactive Oxygen Species in Tumor Necrosis Factor-alpha Induced Endothelial Dysfunction. Curr Hypertens Rev. 2008; 4(4): 245-55.

[80] Kudryavtsev IV, Garnyuk VV, Nadeev AD, Goncharov NV. Hydrogen peroxide modulates expression of surface antigens by human umbilical vein endothelial cells in vitro. Biochemistry (Moscow) Supp. S. A: Membrane and Cell Biology, 2014, 8 (1): 97-102.

[81] Bertrand-Thiebault C, Masson C, Siest G, Batt AM, Visvikis-Siest S. Effect of HMGCoA reductase inhibitors on cytochrome P450 expression in endothelial cell line. J Cardiovasc Pharmacol. 2007; 49(5): 306-15.

[82] Thum T, Borlak J. Mechanistic role of cytochrome p450 monooxygenases in oxidized low-density lipoprotein-induced vascular injury: therapy through LOX-1 receptor antagonism? Circ Res 2004; 94: e1-e13.

[83] Verhaar MC, Westerweel PE, van Zonneveld AJ, Rabelink TJ. Free radical production by dysfunctional eNOS. Heart. 2004;90 (5): 494-5. 
[84] Sánchez A, Contreras C, Martínez MP, et al. Role of neural NO synthase (nNOS) uncoupling in the dysfunctional nitrergic vasorelaxation of penile arteries from insulin-resistant obese Zucker rats. PLoS One. 2012; 7(4): e36027.

[85] Kar S, Kavdia M. Modeling of biopterin-dependent pathways of eNOS for nitric oxide and superoxide production. Free Radic Biol Med 2011; 51(7): 1411-27.

[86] Huang H, Koelle P, Fendler M, et al. Induction of inducible nitric oxide synthase (iNOS) expression by oxLDL inhibits macrophage derived foam cell migration. Atherosclerosis. 2014; 235(1): 213-22.

[87] Freed JK, Beyer AM, LoGiudice JA, Hockenberry JC, Gutterman DD. Ceramide Changes the Mediator of Flow-Induced Vasodilation from Nitric Oxide to Hydrogen Peroxide in the Human Microcirculation. Circ Res 2014 Jun 11. [Epub ahead of print]].

[88] Zamocky M, Jakopitsch C, Furtmüller PG, Dunand C, Obinger C. The peroxidase-cyclooxygenase superfamily: Reconstructed evolution of critical enzymes of innate immune system. Proteins 2008; 72(2): 589605.

[89] Furtmüller PG, Zederbauer M, Jantschko W, et al. Active site structure and catalytic mechanisms of human peroxidases. Arch Biochem. Biophys.2006; 445(2): 199-213.

[90] Heinecke JW, Li W, Francis GA, Goldstein JA. Tyrosyl radical generated by myeloperoxidase catalyzes the oxidative cross-linking of proteins. J Clin Invest. 1993; 91(6): 2866-72.

[91] Sokolov AV, Kostevich VA, Runova OL, et al. Proatherogenic modification of LDL by surfacebound myeloperoxidase. Chem Phys Lipids 2014; 180: 72-80.

[92] Haraguchi Y, Toh R, Hasokawa M, et al. Serum myeloperoxidase/paraoxonase 1 ratio as potential indicator of dysfunctional high-density lipoprotein and risk stratification in coronary artery disease. Atherosclerosis 2014; 234(2): 288-94.

[93] Shao B, Tang C, Sinha A, et al. Humans with atherosclerosis have impaired ABCA1 cholesterol efflux and enhanced high-density lipoprotein oxidation by myeloperoxidase. Circ Res. 2014; 114(11): 1733-42.

[94] Dickerhof N, Magon NJ, Tyndall JD, Kettle AJ, Hampton MB. Potent inhibition of macrophage migration inhibitory factor (MIF) by myeloperoxidase (MPO)-dependant oxidation of epicatechins. Biochem J 2014. [Epub ahead of print]

[95] Piatt J, O'Brien PJ. Singlet oxygen formation by a peroxidase, H2O2 and halide system. Eur J Biochem 1979; 93(2): 323-32. 
[96] Wever R, Kast WM, Kasinoedin JH, Boelens R. The peroxidation of thiocyanate catalysed by myeloperoxidase and lactoperoxidase. Biochim Biophys Acta 1982; 709 (2): 212-9.

[97] Carlsson J, Edlund MB, Hänström L (1984). "Bactericidal and cytotoxic effects of hypothiocyanitehydrogen peroxide mixtures". Infect Immun 1984; 44 (3): 581-6.

[98] Ghibaudi EM, Laurenti E, Beltramo P, Ferrari RP. Can estrogenic radicals, generated by lactoperoxidase, be involved in the molecular mechanism of breast carcinogenesis? Redox Rep 2000; 5(4): 229-35.

[99] Gorlewska-Roberts KM, Teitel CH, Lay JO, Roberts DW, Kadlubar FF. Lactoperoxidase-catalyzed activation of carcinogenic aromatic and heterocyclic amines". Chem. Res. Toxicol. 2004; 17 (12): 1659-66.

[100] Harrison JE, Saeed FA. Radical acetoacetate oxidation by myeloperoxidase, lactoperoxidase, prostaglandin synthetase, and prostacyclin synthetase: implications for atherosclerosis. Biochem Med 1983; 29(2): 149-63.

[101] Mayeno AN, Curran AJ, Roberts RL, Foote CS. Eosinophils preferentially use bromide to generate halogenating agents. J Biol Chem 1989; 264 (10): 5660-8.

[102] Ten RM, Pease LR, McKean DJ, Bell MP, Gleich GJ. Molecular cloning of the human eosinophil peroxidase. Evidence for the existence of a peroxidase multigene family J Exp Med 1989; 169 (5): 1757-69.

[103] Nagata M. Inflammatory cells and oxygen radicals. Curr Drug Targets Inflamm Allergy. 2005;4(4):503-4;

[104] Trillo AA. The cell population of aortic fatty streaks in African green monkeys with special reference to granulocytic cells. An ultrastructural study. Atherosclerosis 1982; 43(2-3): 259-75.

[105] Fukui M, Tanaka M, Hamaguchi M, et al. Eosinophil count is positively correlated with albumin excretion rate in men with type 2 diabetes. Clin J Am Soc Nephrol. 2009;4(11):1761-5.

[106] Gupta K, Selinsky BS, Kaub CJ, Katz AK, Loll PJ. The 2.0 A resolution crystal structure of prostaglandin H2 synthase-1: structural insights into an unusual peroxidase. J Mol Biol. 2004; 335(2): 503-18.

[107] Jaimes EA, Hua P, Tian RX, Raij L. Human glomerular endothelium: interplay among glucose, free fatty acids, angiotensin II, and oxidative stress. Am J Physiol Renal Physiol. 2010; 298(1): F125-32.

[108] Chen CC, Cheng YY, Chen SC, Tuan YF, Chen YJ, Chen CY, Chen LC. Cyclooxygenase-2 expression is up-regulated by 2-aminobiphenyl in a ROS and MAPK-dependent signaling pathway in a bladder cancer cell line. Chem Res Toxicol. 2012; 25(3): 695-705.

[109] Kunz A, Anrather J, Zhou P, Orio M, Iadecola C. Cyclooxygenase-2 does not contribute to postischemic production of reactive oxygen species. J Cereb Blood Flow Metab. 2007; 27(3): 545-51.

[110] Holland JA, Pritchard KA, Pappolla MA, et al. Bradykinin induces superoxide anion release from human endothelial cells. J Cell Physiol 1990; 143: 21-5. 
[111] Ahmed S, Gul S, Gul H, Zia-Ul-Haq M, Ercisli S. Cyclooxygenase-2 inhibition improves antioxidative defense during experimental hypercholesterolemia. Bosn J Basic Med Sci. 2014; 14(2): 63-9.

[112] Kirkby NS, Lundberg MH, Wright WR, et al. COX-2 Protects against Atherosclerosis Independently of Local Vascular Prostacyclin: Identification of COX-2 Associated Pathways Implicate Rgl1 and Lymphocyte Networks. PLoS One. 2014; 9(6): e98165.

[113] Tang SY, Monslow J, Todd L, Lawson J, Puré E, FitzGerald GA. Cyclooxygenase-2 in endothelial and vascular smooth muscle cells restrains atherogenesis in hyperlipidemic mice. Circulation. 2014; 129(17): 1761-9.

[114] Kraus S, Naumov I, Shapira S, et al. Aspirin but not meloxicam attenuates early atherosclerosis in apolipoprotein E knockout mice. Isr Med Assoc J 2014; 16(4): 233-8.

[115] Cho KJ, Seo JM, Kim JH. Bioactive lipoxygenase metabolites stimulation of NADPH oxidases and reactive oxygen species. Mol Cells 2011; 32(1):1-5.

[116] Anwar Y, Sabir JS, Qureshi MI, Saini KS. 5-lipoxygenase: a promising drug target against inflammatory diseases-biochemical and pharmacological regulation. Curr Drug Targets 2014; 15(4): 410-22.

[117] Czapski GA, Czubowicz K, Strosznajder RP. Evaluation of the antioxidative properties of lipoxygenase inhibitors. Pharmacol Rep 2012; 64(5): 1179-88.

[118] Chen W, Lin YC, Ma XY, Jiang ZY, Lan SP. High concentrations of genistein exhibit pro-oxidant effects in primary muscle cells through mechanisms involving 5-lipoxygenase-mediated production of reactive oxygen species. Food Chem Toxicol 2014; 67-72.

[119] Weaver JR, Holman TR, Imai Y, et al. Integration of pro-inflammatory cytokines, 12-lipoxygenase and NOX-1 in pancreatic islet beta cell dysfunction. Mol Cell Endocrinol 2012; 358(1): 88-95.

[120] Kotla S, Singh NK, Heckle MR, Tigyi GJ, Rao GN. The transcription factor CREB enhances interleukin17A production and inflammation in a mouse model of atherosclerosis. Sci Signal 2013; 6(293): ra83.

[121] Sidell B, O'Brien K. When bad things happen to good fish: the loss of hemoglobin and myoglobin expression in Antarctic icefishes. J Exp Biol 2006; 209(Pt 10): 1791-802.

[122] Weed RI; Reed CF, Berg G. Is hemoglobin an essential structural component of human erythrocyte membranes? J Clin Invest. 1963; 42(4): 581-8.

[123] Gunsalus IC, Sligar SG, Nordlund T, Frauenfelder H. Oxygen sensing heme proteins: monoxygenases, myoglobin and hemoglobin. Adv Exp Med Biol 1977; 78: 37-50.

[124] Lopez-Barneo J, Ortega-Saenz P, Molina A, Franco-Obregon A, Urena J, Castellano A. Oxygen sensing by ion channels. Kidney Int 51: 454-461, 1997; 
[125] Acker T, Fandrey J, Acker H. The good, the bad and the ugly in oxygen-sensing: ROS, cytochromes and prolyl-hydroxylases. Cardiovasc Res 2006; 71: 195-207.

[126] Ryter SW, Tyrrell RM. The heme synthesis and degradation pathways: role in oxidant sensitivity. Heme oxygenase has both pro- and antioxidant properties. Free Radic Biol Med 2000; 28: 289-309.

[127] Abugo OO, Rifkind JM. Oxidation of hemoglobin and the enhancement produced by nitroblue tetrazolium. J Biol Chem 1994; 269, 24845-53.

[128] Silva G, Jeney V, Chora A, et al. Oxidized hemoglobin is an endogenous proinflammatory agonist that targets vascular endothelial cells. J Biol Chem 2009; 284: 29582-95.

[129] Balagopalakrishna C, Manoharan PT, Abugo OO, Rifkind JM. Production of superoxide from hemoglobinbound oxygen under hypoxic conditions. Biochemistry 1996; 35: 6393-8.

[130] Cao Z, Bell JB, Mohanty JG, Nagababu E, Rifkind JM. Nitrite enhances RBC hypoxic ATP synthesis and the release of ATP into the vasculature: a new mechanism for nitrite-induced vasodilation. Am J Physiol Heart Circ Physiol 2009; 297: H1494-503.

[131] Nagababu E., Gulyani S., Earley CJ, et al. Iron-deficiency anaemia enhances red blood cell oxidative stress. Free Radic. Res. 208; 42, 824-9.

[132] Kiefmann R, Rifkind JM, Nagababu E, Bhattacharya J. Red blood cells induce hypoxic lung inflammation. Blood 2008; 111, 5205-14.

[133] Huertas A, Das SR, Emin M, et al. Erythrocytes induce proinflammatory endothelial activation in hypoxia. Am J Respir Cell Mol Biol 2013; 48, 78-86.

[134] Gurbuz N, Yalcin O, Aksu TA, Baskurt OK. The relationship between the enzyme activity, lipid peroxidation and red blood cells deformability in hemizygous and heterozygous glucose-6-phosphate dehydrogenase deficient individuals. Clin Hemorheol Microcirc 2004; 31, 235-42.

[135] Chasis JA, Mohandas N. Erythrocyte membrane deformability and stability: two distinct membrane properties that are independently regulated by skeletal protein associations. J Cell Biol. 1986; 103, 343-50.

[136] Suzuki Y, Ohkubo N, Aoto M, et al. Participation of caspase-3-like protease in oxidation-induced impairment of erythrocyte membrane properties. Biorheology 2007; 44, 179-90.

[137] Grau M, Pauly S, Ali J, et al. RBC-NOS-dependent S-nitrosylation of cytoskeletal proteins improves RBC deformability. PLoS ONE 2013; 8: e56759. 
[138] Mandal D, Baudin-Creuza V, Bhattacharyya A, et al. (2003). Caspase 3-mediated proteolysis of the Nterminal cytoplasmic domain of the human erythroid anion exchanger 1 (band 3). J Biol Chem 2003; 2786 52551-8.

[139] Mandal D, Mazumder A, Das P, Kundu M, Basu J. Fas-, caspase 8-, and caspase 3-dependent signaling regulates the activity of the aminophospholipid translocase and phosphatidylserine externalization in human erythrocytes. J Biol Chem 2005; 280: 39460-7/

[140] Grey JL, Kodippili GC, SimonK, Low PS. Identification of contact sites between ankyrin and band 3 in the human erythrocyte membrane. Biochemistry 2012; 51: 6838-46.

[141] Mindukshev IV, Senchenkova EY, Goncharov NV, Vivulanets EV, Krivoshlyk VV. New methods for studying platelets and red blood cells, based upon the low-angle light scattering technique. In: Hemorheology: Blood Flow, Disturbance and Prognosis. Ed.F.Columbus, NY, Nova Science Publishers 2010; 87-124.

[142] Fens MH, van Wijk R, Andringa G, et al. A role for activated endothelial cells in red blood cell clearance: implications for vasopathology. Haematologica 2012; 97: 500-8.

[143] Kiefer CR, Snyder LM. Oxidation and erythrocyte senescence. Curr Opin Hematol 2000; 7: 113-6.

[144] Barodka V, Mohanty JG, Mustafa AK, et al. Nitroprusside inhibits calcium-induced impairment of red blood cell deformability. Transfusion 2013; 54: 434-44.

[145] Mindukshev IV, Krivoshlyk VV, Ermolaeva EE, et al. Necrotic and apoptotic volume changes of red blood cells investigated by low-angle light scattering technique. Spectroscopy Int J 2007; 21(2): 105-20.

[146] Redding GS, Record DM, Raess BU. Calcium-stressed erythrocyte membrane structure and function for assessing glipizide effects on transglutaminase activation. Proc Soc Exp Biol Med 1991; 196, 76-82.

[147] Zipser Y, Piade A, Barbul A, Korenstein R, Kosower NS. Ca2+ promotes erythrocyte band 3 tyrosine phosphorylation via dissociation of phosphotyrosine phosphatase from band 3. Biochem J 2002; 368, 137-44.

[148] Farbstein D, Soloveichik YZ, Levy NS, Levy AP. Genetics of redox systems and their relationship with cardiovascular disease. Curr Atheroscler Rep 2011; 13: 215-24.

[149] Martin-Ventura JL, Madrigal-Matute J, Martinez-Pinna R, et al. Erythrocytes, leukocytes and platelets as a source of oxidative stress in chronic vascular diseases: detoxifying mechanisms and potential therapeutic options. Thromb Haemost 2012; 108(3): 435-42.

[150] Nagy E, Eaton JW, Jeney V, et al. Red cells, hemoglobin, heme, iron, and atherogenesis. Arterioscler Thromb Vasc Biol 2010; 30: 1347-53. 
[151] Boyle JJ, Johns M, Lo J, et al. Heme Induces Heme Oxygenase 1 via Nrf2: Role in the Homeostatic Macrophage Response to Intraplaque Hemorrhage. Arterioscler Thromb Vasc Biol 2011; 31: 2685-91.

[152] Finn AV, Nakano M, Polavarapu R, et al. Hemoglobin directs macrophage differentiation and prevents foam cell formation in human atherosclerotic plaques. J Am Coll Cardiol 2012; 59: 166-77.

[153] Watanabe J, Chou KJ, Liao JC, et al. Differential association of hemoglobin with proinflammatory high density lipoproteins in atherogenic/hyperlipidemic mice. A novel biomarker of atherosclerosis. J Biol Chem 2007; 282: 23698-707.

[154] Crawford JH, Isbell TS, Huang Z, et al. Hypoxia, red blood cells, and nitrite regulate NO-dependent hypoxic vasodilation. Blood 2006; 107: 566-74.

[155] Minneci PC, Deans KJ, Shiva S, et al. Nitrite reductase activity of hemoglobin as a systemic nitric oxide generator mechanism to detoxify plasma hemoglobin produced during hemolysis. Am J Physiol Heart Circ Physiol 2008; 295: H743-54.

[156] Jeney V, Balla J, Yachie A, et al. Pro-oxidant and cytotoxic effects of circulating heme. Blood 2002; 100: 879-87.

[157] Ball RY, Bindman JP, Carpenter KL, Mitchinson MJ Oxidized low density lipoprotein induces ceroid accumulation by murine peritoneal macrophages in vitro. Atherosclerosis 1986; 60: 173-81.

[158] Ball RY, Carpenter KL, Mitchinson MJ. What is the significance of ceroid in human atherosclerosis? Arch Pathol Lab Med 1987; 111: 1134-40.

[159] Lee FY, Lee TS, Pan CC, et al. Colocalization of iron and ceroid in human atherosclerotic lesions. Atherosclerosis 1998; 138: 281-8.

[160] Haka AS, Kramer JR, Dasari RR, Fitzmaurice M. Mechanism of ceroid formation in atherosclerotic plaque: in situ studies using a combination of Raman and fluorescence spectroscopy. J Biomed Opt 2011; 16 : 011011.

[161] Brissot P, Ropert M, Le Lan C, Loréal O. Non-transferrin bound iron: A key role in iron overload and iron toxicity. Biochim Biophys Acta 2012; 1820: 403-10.

[162] Ray PD, Huang BW, Tsuji Y. Reactive oxygen species (ROS) homeostasis and redox regulation in cellular signaling. Cell Signal 2012; 24: 981-90.

[163] Stadler N, Lindner RA, Davies MJ. Direct detection and quantification of transition metal ions in human atherosclerotic plaques: evidence for the presence of elevated levels of iron and copper. Arterioscler Thromb Vasc Biol 2004; 24: 949-54. 
[164] Stanley N, Stadler N, Woods AA, Bannon PG, Davies MJ. Concentrations of iron correlate with the extent of protein, but not lipid, oxidation in advanced human atherosclerotic lesions. Free Radic Biol Med 2006; 40: 1636-43.

[165] Nchimi A, Defawe O, Brisbois D, et al. MR imaging of iron phagocytosis in intraluminal thrombi of abdominal aortic aneurysms in humans. Radiology 2010; 254: 973-81.

[166] Leopold JA, Loscalzo J. Oxidative enzymopathies and vascular disease. Arterioscler Thromb Vasc Biol 2005; 25(7): 1332-40.

[167] Gardner PR, Nguyen DD, White CW. Aconitase is a sensitive and critical target of oxygen poisoning in cultured mammalian cells and in rat lungs. Proc Natl Acad Sci USA 1994; 91 (25): 12248-52.

[168] Mohr S, Hallak H, de Boitte A, Lapetina EG, Brüne B. Nitric oxide-induced S-glutathionylation and inactivation of glyceraldehyde-3-phosphate dehydrogenase. J Biol Chem 1999; 274 (14), 9427-30.

[169] Matsuda M, Shimomura I. Increased oxidative stress in obesity: implications for metabolic syndrome, diabetes, hypertension, dyslipidemia, atherosclerosis, and cancer. Obes Res Clin Pract. 2013 ;7(5): e330-41.

[170] Nemoto S, Takeda K, Yu ZX, Ferrans VJ, Finkel T. Role for mitochondrial oxidants as regulators of cellular metabolism. Mol Cell Biol 2000; 20: 7311-8.

[171] Brunelle JK, Bell EL, Quesada NM, et al. Oxygen sensing requires mitochondrial ROS but not oxidative phosphorylation. Cell Metab 2005; 1: 409-14.

[172] Mansfield KD, Guzy RD, Pan Y, et al. Mitochondrial dysfunction resulting from loss of cytochrome c impairs cellular oxygen sensing and hypoxic HIF-alpha activation. Cell Metab 2005; 1: 393-9.

[173] Scherz-Shouval R, Shvets E, Fass E, et al. Reactive oxygen species are essential for autophagy and specifically regulate the activity of Atg4. EMBO J 2007; 26: 1749-60.

[174] Bulua AC, Simon A, Maddipati R, et al. Mitochondrial reactive oxygen species promote production of proinflammatory cytokines and are elevated in TNFR1-associated periodic syndrome (TRAPS). J Exp Med 2011; 208: 519-33.

[175] Nakahira K, Haspel JA, Rathinam VA, et al. Autophagy proteins regulate innate immune responses by inhibiting the release of mitochondrial DNA mediated by the NALP3 inflammasome. Nat Immunol 2011; 12: 222-30.

[176] Zhou R, Yazdi AS, Menu P, Tschopp J. A role for mitochondria in NLRP3 inflammasome activation. Nature 2011; 469: 221-5. 
[177] Rus HG, Niculescu F, Vlaicu R. Tumor necrosis factor-alpha in human arterial wall with atherosclerosis. Atherosclerosis 1991; 89: 247-54.

[178] Buono C, Come CE, Stavrakis G, et al. Influence of interferon-gamma on the extent and phenotype of dietinduced atherosclerosis in the LDLR-deficient mouse. Arterioscler Thromb Vasc Biol 2003; 23: 454-60.

[179] Kirii H, Niwa T, Yamada Y, et al. Lack of interleukin-1beta decreases the severity of atherosclerosis in ApoE-deficient mice. Arterioscler Thromb Vasc Biol 2003; 23: 656-60.

[180] Razani B, Feng C, Coleman T, et al. Autophagy links inflammasomes to atherosclerotic progression. Cell Meta. 2012; 15(4): 534-44.

[181] Liao X, Sluimer JC, Wang Y, et al. Macrophage autophagy plays a protective role in advanced atherosclerosis. Cell Metab. 2012; 15(4): 545-53.

[182] Alom-Ruiz SP, Anilkumar N, Shah AM. Reactive oxygen species and endothelial activation. Antioxid Redox Signal 2008; 10: 1089-1100

[183] van Hinsbergh VW. Endothelium-role in regulation of coagulation and inflammation. Semin Immunopathol 2012; 34(1): 93-106.

[184] Libby P, Plutzky J. Inflammation in diabetes mellitus: role of peroxisome proliferator-activated receptoralpha and peroxisome proliferator-activated receptor-gamma agonists. Am J Cardiol 2007; 99: 27B-40B.

[185] Garcia-Cardena G, Gimbrone MA Jr. Biomechanical modulation of endothelial phenotype: implications for health and disease. Handb Exp Pharmacol 2006; 79-95.

[186] Fischer B, von Knethen A, Brune B. Dualism of oxidized lipoproteins in provoking and attenuating the oxidative burst in macrophages: role of peroxisome proliferator-activated receptor-gamma. J Immunol 2002; 168: 2828-34.

[187] Libby P. Inflammation in atherosclerosis. Nature. 2002; 420: 868-74.

[188] Galkina E, Ley K. Vascular adhesion molecules in atherosclerosis. Arterioscler Thromb Vasc Biol 2007; 27: 2292-01.

[189] Kisucka J, Chauhan AK, Patten IS, et al. Peroxiredoxin1 prevents excessive endothelial activation and early atherosclerosis. Circ Res 2008;103(6): 598-605.

[190] Vischer UM, Jornot L, Wollheim CB, Theler JM. Reactive oxygen intermediates induce regulated secretion of von Willebrand factor from cultured human vascular endothelial cells. Bloo. 1995; 85: 3164-72.

[191] Lowenstein CJ, Morrell CN, Yamakuchi M. Regulation of Weibel-Palade body exocytosis. Trends Cardiovasc Med. 2005; 15: 302-8. 
[192] Dole VS, Bergmeier W, Mitchell HA, Eichenberger SC, Wagner DD. Activated platelets induce WeibelPalade-body secretion and leukocyte rolling in vivo: role of P-selectin. Blood. 2005; 106: 2334-9/

[193] Larsen GR, Sako D, Ahern TJ, et al. P-selectin and E-selectin. Distinct but overlapping leukocyte ligand specificities. J Biol Chem 1992; 267 (16), 11104-10.

[194] Scialla JJ, Plantinga LC, Kao WH, et al. Soluble P-selectin levels are associated with cardiovascular mortality and sudden cardiac death in male dialysis patients. Am J Nephrol 2011; 33(3): 224-30.

[195] Rondaij MG, Bierings R, Kragt A, et al. Dynamics and plasticity of Weibel-Palade bodies in endothelial cells. Arterioscler Thromb Vasc Biol. 2006; 26(5):1002-7.

[196] Chauhan AK, Kisucka J, Brill A, et al. ADAMTS13: a new link between thrombosis and inflammation. J Exp Med 2008, 205(9): 2065-74/

[197] Fiedler U, Scharpfenecker M, Koidl S, et al. The Tie-2 ligand angiopoietin-2 is stored in and rapidly released upon stimulation from endothelial cell Weibel-Palade bodies. Blood. 2004; 103: 4150-6.

[198] Øynebråten I, Bakke O, Brandtzaeg P, et al. Rapid chemokine secretion from endothelial cells originates from 2 distinct compartments. Blood 2004; 104(2): 314-20.

[199] Valentijn KM, Sadler JE, Valentijn JA, et al. Functional architecture of Weibel-Palade bodies. Blood 2011; 117(19): 5033-43.

[200] Babich V, Knipe L, Hewlett L, et al. Differential effect of extracellular acidosis on the release and dispersal of soluble and membrane proteins secreted from the Weibel-Palade body. J Biol Chem 2009; 284(18): 12459-68.

[201] Djordjevic T, Pogrebniak A, BelAiba RS, et al. The expression of the NADPH oxidase subunit p22phox is regulated by a redox-sensitive pathway in endothelial cells. Free Radic Biol Med 2005; 38(5): 616-30.

[202] Thakur S, Du J, Hourani S, et al. Inactivation of adenosine A2A receptor attenuates basal and angiotensin II-induced ROS production by Nox2 in endothelial cells. J Biol Chem 2010; 285(51): 40104-13.

[203] Kovacic HN, Irani K, Goldschmidt-Clermont PJ. Redox regulation of human Rac1 stability by the proteasome in human aortic endothelial cells. J Biol Chem 2001; 276: 45856-61,

[204] Li WG, Miller FJ Jr., Zhang HJ, et al. $\mathrm{H}_{2} \mathrm{O}_{2}$-induced $\mathrm{O}_{2}$ production by a non-phagocytic NAD(P)H oxidase causes oxidant injury. J Biol Chem 2001; 276: 29251-56, 